ISSN: 0514-7336 — ISSN electrónico: 2386-3943

DOI: https://doi.org/10.14201/zephyrus202188163189

\title{
EL SISTEMA DE RELACIÓN CONTINUA EN LA PINTURA MURAL ROMANA DE HISPANIA
}

\section{Carper Style in the Roman Wall Painting of Hispania}

\author{
Lara Íñiguez Berrozpe* y Carmen Guiral Pelegrín** \\ *Dpto. de Patrimonio. Escuela de Turismo Universitaria de Zaragoza. Plaza Ecce Homo, 3. 50003 Zaragoza. \\ Correo-e: laraib@unizar.es. ID ORCID: https://orcid.org/0000-0001-5006-8693 \\ ** Dpto. de Prehistoria y Arqueología. Facultad de Geografía e Historia-UNED. C/ Senda del Rey, 7. 28040 Madrid. \\ Correo-e: cguiral@geo.uned.es.ID ORCID: https://orcid.org/0000-0002-3391-4736
}

Recepción: 21/03/2021; Revisión: 14/07/2021; Aceptación: 1/11/2021

Resumen: Planteamos en este trabajo el estudio, basado en una metodología descriptiva comparativa, y la puesta al día de un sistema decorativo consistente en la repetición ordenada de un módulo, cuyos motivos suelen representarse de forma independiente, tangente o secante; la trama geométrica resultante puede adornarse con elementos geométricos, vegetales y figurados, o una combinación de los tres. Se estudian en profundidad dos de los motivos ornamentales más repetidos: las cabezas femeninas y las plumas de pavo. Este esquema compositivo es característico de la ornamentación de los techos y de la zona superior de la pared, si bien, y en menor medida, también puede ocupar la totalidad de la zona media. En la pintura hispana aparece en época de Tiberio y perdura hasta el s. vi y gracias al estudio en regiones concretas, se han podido establecer relaciones de taller.

Palabras clave: Península Ibérica; esquema compositivo; cabezas femeninas mofletudas; plumas de pavo; talleres; fondo blanco.

AвSTRACT: We propose in this work the study, based on a comparative descriptive methodology, and an update of a decorative system consisting of the ordered repetition of a module, whose motifs are usually represented independently, tangent or secant; the resulting geometric pattern can be adorned with geometric, vegetal and figurative elements, or a combination of all three. Two of the most repeated ornamental motifs are studied in depth: female heads and turkey feathers. This compositional scheme is characteristic of the ornamentation of the ceilings and the upper area of the wall, although, to a lesser extent, it can also occupy the entire middle area. In Hispanic painting it appears at the time of Tiberius and lasts until the 6th century and, thanks to the study in specific regions, it has been possible to establish workshop relationships.

Key words: Iberian Peninsula; Compositional Scheme; Chubby Female Heads; Turkey Feathers; Workshops; White Background. 


\section{Introducción ${ }^{1}$}

El concepto 'sistema de relación continua'2 supone una traslación a la terminología hispana de diversos términos, tapeten-munster mit unendlichem repport en alemán, système à réseau en francés, wallpaper patterns o carpet style en inglés y carta da parati o tappezzeria en italiano; en el año 2014, en el marco del proyecto italiano TECT, se propuso la utilización de sistema a modulo ripetuto (Didonè et al., 2014: 27). Algunos de estos términos permiten comprobar que en inglés, italiano y alemán este esquema decorativo se identifica con la imitación de los actuales papeles pintados, hecho que nos parece inadecuado ya que este tipo de revestimiento no existía en la Antigüedad; por ello preferimos usar un término relacionado con el diseño, consistente en la repetición de un mismo motivo.

El sistema de relación continua consiste en un esquema compositivo basado en la repetición ordenada de un módulo, cuyos motivos suelen representarse de forma independiente, tangente o secante. Dicha repetición crea una trama geométrica que puede adornarse con elementos geométricos, vegetales y figurados, o una combinación de los tres (Dardenay, 2014: 76-77). El módulo básico tiene la particularidad no solamente de poder repetirse infinitamente sobre la superficie, sino de hacerlo además de forma independiente al eje (lateral, horizontal o vertical) de la composición. Esta decoración implica además la inexistencia de un punto focal, como ocurre con la presencia de una escena figurada o de una representación arquitectónica, y su lectura es la misma desde cualquier punto de vista. Por tanto, no tiene una orientación concreta, siempre y

1 Este trabajo se ha realizado en el marco del proyecto de investigación "Tectoria et pigmenta: estudio analítico y arqueológico de los pigmentos y morteros de las pinturas del cuadrante NE de Hispania (s. II a. C.- s. vi d. C.)" (HAR2017-84732-P), dirigido por C. Guiral y en el que L. Íniguez es miembro del equipo de investigación.

2 Seguimos el término acuñado por Abad (1982: 322 ), aun teniendo en cuenta que peca de ambigüedad y considerando que está arraigado en la terminología de la pintura romana en Hispania.

Ediciones Universidad de Salamanca / @ه্త cuando no exista un elemento iconográfico que nos ayude a ello (Formoso, 2006: 87).

Respecto a su disposición en la estancia, aunque la mayor parte de los ejemplos conservados decoraban cubiertas, en los márgenes cronológicos del IV estilo, tal y como prueban varias paredes de la Península Itálica, descendió hasta situarse en la zona media y/o superior de la pared (De Vos, 1982: 333; Barbet, 1985: 145; Ling, 1991: 84-85) ${ }^{3}$.

También nos interesa destacar que, aunque se trate de la repetición de un mismo módulo, las combinaciones para su diseño son variadísimas. A este respecto, es necesario citar el intento de clasificación y de homogeneización de terminología para referirse a los elementos de cada tipología, realizado por Barbet et al. (1997).

\section{El sistema de relación continua: un lenguaje común}

Cabe preguntarnos ahora cuál es su fuente de inspiración, es decir, si este esquema decorativo imitaba composiciones características de otros soportes.

A este respecto varias hipótesis han sido propuestas (Laken, 2001: 295). Una de las más repetidas es que, independientemente de su ubicación en techos y/o paredes, deriva de la imitación pintada de los conocidos casetones en estuco, decorados en su interior o no, que ornaban las cubiertas, camuflando las vigas entrecruzadas de los techos, lo cual cobra sentido en las composiciones reticulares como la presente en el Triclinio c de la Casa di Pinarius Cerealis -III 4, 4-, entre otras. Incluso los círculos dispuestos en las intersecciones, que veremos en algunas de las pinturas citadas en este estudio, podrían emular los clavos que sostenían dichas vigas, por supuesto representados en pintura con gran libertad (Allag y Vibert-Guigue, 2001-2002: 151).

3 Existe un raro ejemplo, datado en el s. II d. C., en las termas de la villa de Damblain, en el que este tipo de sistema decorativo se posiciona en los interpaneles (Mondy et al., 2012: 220-224). 
También se ha apostado, y así lo recoge Laken, por el mosaico como fuente de inspiración, y es evidente que juega un papel importante como modelo. En la decoración parietal está probada para otro tipo de composiciones y ornamentos no ya la inspiración en el mosaico, sino directamente la imitación del mismo. Así lo podemos comprobar en algunas pinturas de la Bética, en las que se representan las teselas que conforman el opus musivum (Fernández Díaz, 2016a).

Por tanto, podríamos aceptar esta fuente de inspiración para cierto tipo de esquemas; no obstante, no parece ocurrir el mismo fenómeno para otros diseńos, sobre todo aquellos cuyas líneas presentan o se sustituyen por flores, guirnaldas u otros elementos vegetales. Los mosaicos que presentan un sistema de relación continua basado en tramas vegetalizadas nacen en Italia en el s. II d. C., siendo los Hospitalia de la Villa Hadriana donde tiene lugar el origen de este estilo vegetal, para luego extenderse a Ostia, Roma y posteriormente al mundo provincial (Gozlan, 1992: 1654; Darmon, 2001: 111-1195), sin que, de hecho, el elenco sea muy numeroso ${ }^{6}$.

La trama vegetalizada en patrones geométricos existe en las pinturas anteriores al s. II d. C. y citamos como ejemplos el oecus (28) de la Villa de Arianna en Pompeya -VII 4, 31-51; PPM VI 1070-1071, fig.

4 Afirmación realizada a propósito del estudio del mosaico con composición a base de flores insertas en círculos que decora el Cubiculum xxxi de la Casa del Triunfo de Neptuno en Acholla, de finales del s. II d. C.

5 El autor apunta, no sin ciertas dudas, que existe un ejemplo aislado con una datación anterior, el mosaico de Aquileia de tappeto fiorito, de inicios del s. II d. C., según Bertacchi (1963); sin embargo, en la revisión realizada por Rinaldi (2005), se recupera la primera hipótesis cronológica propuesta por Bertacchi en 1962 y fecha el mosaico entre finales del s. II y principios del III d. C. Por otra parte, nos referimos al esquema basado en una trama vegetal. Es evidente que el estilo floral en mosaico tiene sus orígenes en Grecia, tal y como se puede comprobar en el mosaico de Sikyon, datado a mediados del s. Iv a. C., que tendrá especial relevancia en época helenística (Dunbabin, 1999: 10-11, fig. 8).

6 Rinaldi (2005: 403 y ss.) se hace eco de este hecho y recopila los principales mosaicos con decoración vegetalizada.
108-, donde ocupa toda la zona media de la pared; la bóveda del pasillo 92 de la Domus Aurea (Meyboom y Moormann, 2013: fig. 92.14) ${ }^{7}$ o la bóveda de la Estancia a2 de la Domus Transitoria de Roma (Barbet, 1985: 216, fig. 148), datados todos en los márgenes cronológicos del IV estilo. Esto vendría a probar que la trama vegetalizada aparecería antes en la pintura que en el mosaico, lo cual, por un lado, reivindica el papel de la pintura como inspiración para, al menos, este motivo concreto ${ }^{8}$; , por otro, refuerza la idea de la existencia de un evidente lenguaje recíproco para la decoración de suelos, techos y muros, hipótesis expuesta ya por varios autores como, por ejemplo, Barbet (1983': 51-53; 1985: 268; 2003: 330), Ghedini y Salvadori (2004: 51) y Colpo (2004), si bien, como veremos a continuación, la cuestión no es tan sencilla.

Laken propone otras dos posibles fuentes de inspiración para este sistema decorativo: el tapiz y las vallas, de madera o cañas, que rodean los jardines. En cuanto a la primera, efectivamente, varias pinturas parecen emular la decoración textil, como se comprueba en la zona superior de la pared de la Habitación 31 de la Villa de Poppea en Oplontis y en el Triclinium-nymphaeum 14 de la Villa Romana de Minori (Laken, 2001: 297, figs. 3 y 4), ambos con un sistema compuesto por cintas bordadas. Antiguas descripciones indican que la taberna -VII 14,1 - estaba pintada como un tapiz, con una greca continua sobre fondo amarillo -PPM VII, 660-.

7 La bóveda del Ambiente 79, decorada también con un sistema de relación continua, cuenta con cierta vegetalización, aunque más sutil (Meyboom y Moormann, 2013: 108, fig. 79.13).

8 Para otros casos, en los que también se ha comprobado el papel de la pintura como inspiración para el mosaico, véase Barbet, 1985: 268.

9 Es interesante el análisis de la autora sobre el motivo de estrella elaborado con losanges, habitual en sistemas de relación continua. Si bien estaba probada su presencia en mosaico -II estilo- antes que en pintura -III estilo-, demuestra que su aparición tiene lugar en arquitecturas de piedra o estuco, tal y como podemos observar en la pieza de mármol esculpida, del s. I a. C., hallada en la Via Salaria de Roma. Todo ello permite desechar la idea de proponer una única fuente de inspiración para un determinado tipo decorativo. 
En el mundo provincial, sin embargo, los paralelos disminuyen, pudiendo citar solo las pinturas de Thillay, Francia, en las que se representa un auténtico tapiz verde profusamente decorado y bordeado por flecos (Groetembril y Vermeersch, 2017: 103107, figs. 10-11 $)^{10}$.

Parece que el mundo textil no es un agente secundario en el juego decorativo, no solo ya porque lo encontremos representado claramente en multitud de ejemplos pictóricos en Próximo Oriente, Grecia helenística y por supuesto en pintura mural romana ${ }^{11}$, sino porque, como ya apuntara Scagliarini (1985-1987: 580), también existen muchos pavimentos teselados que emulan claramente un tapiz, como el procedente de la Casa de Synaristôsai en Zeugma, en el que se representan dos pequeñas alfombras (Abadie-Reynal y Darmon, 2003: 84, fig. 7). En este sentido, volvemos a traer a colación el mosaico de tappeto fiorito de Aquileia, con un diseño vegetalizado.

Si atendemos a la tercera posibilidad planteada por Laken (2001: 297-298), algunos de los sistemas en relación continua podrían identificarse con la representación esquemática de los canceles de jardín $^{12}$. La autora reconoce que puede tratarse de la fuente más indirecta y propone para ello paralelos donde la decoración, siempre con algún elemento vegetal, se dispone en la parte inferior del muro o bien ocupa toda la zona media. En cualquier caso, no debemos desdeñar esta posibilidad para sistemas de relación continua situados en la zona superior de la pared, pues el conjunto hallado en la rue du Hâ en Burdeos (Tessariol, 2016: 26-29, fig. 1), demuestra

10 Existe un paralelo similar, sobre fondo rojo, en las pinturas halladas en el colegio Sainte-Barbe de París, cuya datación no es anterior al s. II d. C. Gracias al reverso se concluye que perteneció a la decoración del muro, pero su mala conservación impide comprobar si se trata de un tapiz y la zona del muro a la que se adscribe (Eristov y Robin, 2011: 155, fig. 6a).

11 Recomendamos la lectura de Groetembril y Vermmersh (2017: 108) para la consulta de los ejemplos existentes en cada uno de estos territorios.

12 No incidimos con más profundidad en este tema, puesto que ha sido objeto de estudio por Salvadori (2017), en su obra sobre los jardines en la pintura romana. que puede existir representación de jardines en esta zona.

En resumen, no podemos otorgar un papel preponderante a la pintura, al mosaico o a los textiles como fuente de inspiración para los sistemas de relación continua. Sin duda existe un origen común y los distintos soportes se influenciaron entre ellos, lo cual evidencia la gran variedad de composiciones y complica cualquier síntesis o clasificación.

Con objeto de analizar este sistema compositivo en la pintura hispana, vamos a organizar los distintos ejemplos de acuerdo al lugar que ocuparon en la decoración general de la estancia.

\section{Sistemas de relación continua en techos y bóvedas}

En este apartado solo se tienen en cuenta las decoraciones de techos. Aquellas estancias en las que este tipo decorativo ocupa la cubierta y la zona superior se estudiarán en el apartado siguiente ${ }^{13}$.

El techo pintado más antiguo con este sistema decorativo conservado en la actualidad en Hispania ${ }^{14}$ procede de la parte abovedada de la cubierta de la Estancia 12 de la Casa de los Delfines de Celsa, Velilla de Ebro, Zaragoza (Fig. 1a), fechado entre los años 35 y $45 \mathrm{~d}$. C. Sobre un fondo negro, filetes amarillos se entrecruzan formando casetones, en cuyo interior se inscriben dos circunferencias concéntricas con rosetas centrales; esta composición está rodeada por una banda roja, y se interrumpe por cuatro emblemas con Nereidas en los ángulos y un emblema central con Venus marina cabalgando sobre tritones (Mostalac y Beltrán, 1994: 87-124).

A mediados del s. I d. C. se fecha el techo de la Tumba de Servilia en Carmona, Sevilla (Fig. 1b), decorado con una composición ortogonal en la que

13 Por cuestiones de espacio, no se van a tener en cuenta las decoraciones realizadas en estuco.

14 El gran número de paralelos de techos con sistemas de relación continua nos impide presentar aquí una síntesis. Para una introducción a los techos pintados vid. Barbet, 1985: 215-220 y Ling, 1991: 85-99. 
a)

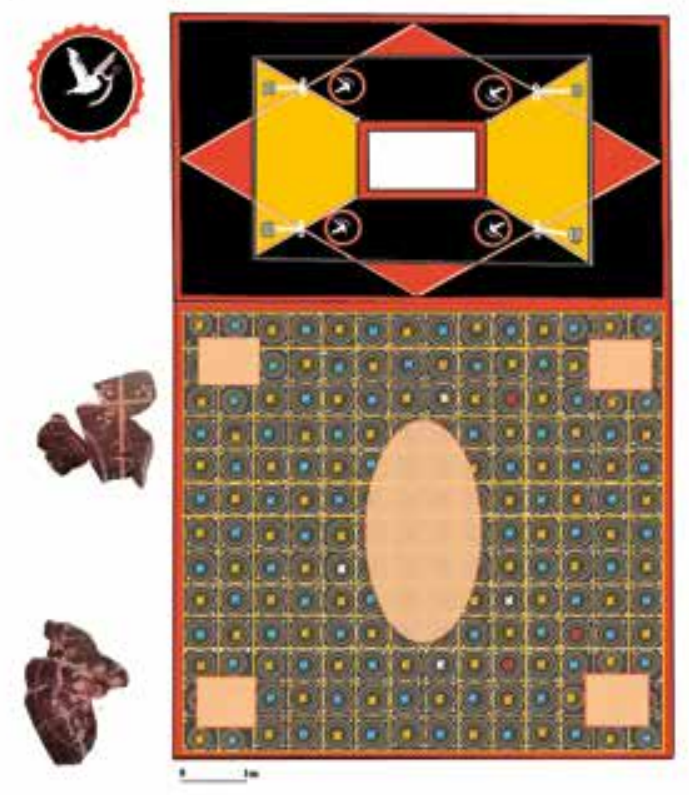

b)

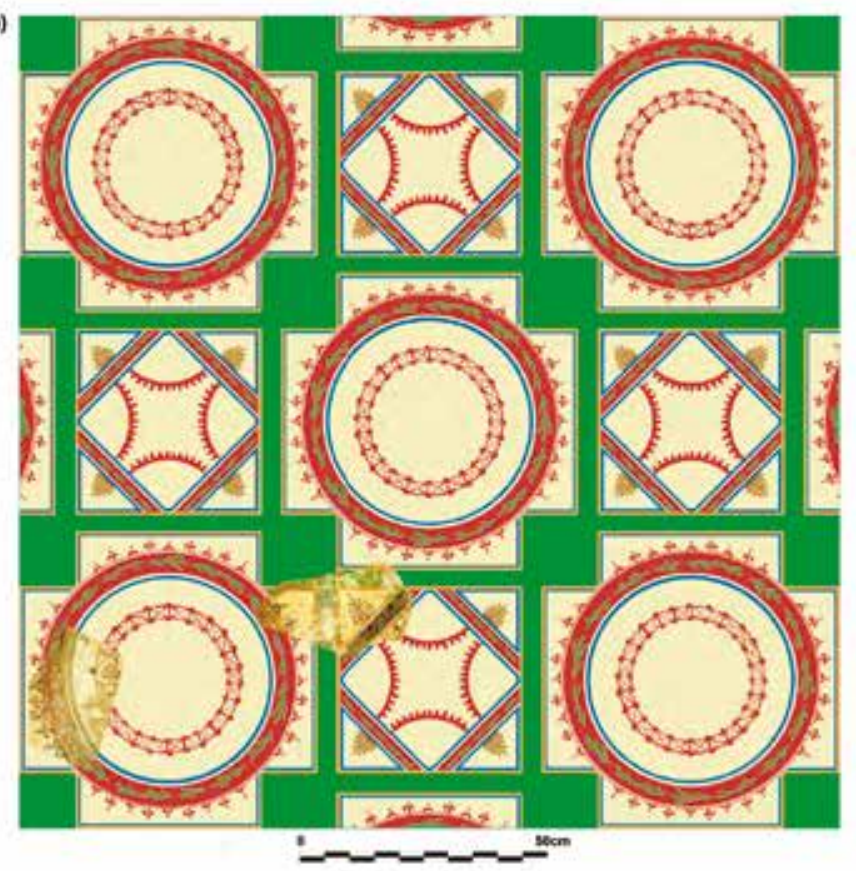

Fig. 1. Techos fechados en el s. I d. C. con sistema de relación continua basado en la imitación de casetones: a) Estancia 12 de la Casa de los Delfines de Celsa (dibujo de la Escuela Taller de Restauración de Aragón); b) Tumba de Servilia en Carmona (Abad, 1982; digitalización de Fernández Diaz, 2014: 143, fig. 300).

alternan círculos inscritos en cruces y rombos inscritos en cuadrados (Abad, 1982: 189-190).

La mayor parte de los techos conservados se fechan en el s. II d. C. Algunos siguen fieles a la imitación de casetones cuadrangulares: en el techo de la casa del Sector 5e de la Colonia Iulia Ilici Augusta, Elche (Fig. 2a), sobre fondo rojo, se desarrollan los casetones de color verde con cuadrados inscritos de fondo rojo, mientras que en los casetones de color anaranjado estos cuadrados son negros; ambos decorados con flores cuadripétalas (Abad, 1982: 32; Fernández Díaz, 2004b: 167-174). Por nuestra parte, no descartamos que las cabezas femeninas mofletudas halladas en el mismo sector se ubicasen en el centro de los casetones. Muy similar al anterior es el techo del Cubiculum 5 de la Domus del Sátiro de Corduba, Córdoba, también con casetones verdes y rojos enmarcados en blanco y con rosetas en su interior (Castro y Cánovas, 2010: 135; Cánovas, 2010: 434-435). Finalmente, en el techo procedente de las estancias anteriores de la denominada
Domus de Terpsícore en Valentia, Valencia (López et al., 1994: 157, lám. 50) (Fig. 2b), la imitación de casetones se realiza sobre color blanco, que será el característico del s. II; además, la decoración es más compleja, con palmetas estilizadas en las bandas de enmarque y círculos rojos en las intersecciones ${ }^{15}$.

En la misma centuria existen otras decoraciones que no imitan casetones stricto sensu, sino otras figuras geométricas más complejas, pero que, evidentemente, derivan de ellos. En la bóveda de la tumba de Vildé (Soria) (Fig. 3a) la composición es ortogonal, sobre fondo verde, con octógonos irregulares adyacentes que definen cuadrados que apoyan sobre el vértice (Abad, 1982: 247). También la bóveda del caldarium del conjunto termal

15 Este espacio ha sido objeto de distintas interpretaciones, si bien en la publicación más reciente se expone con claridad que no existen datos para discernir si se trataba de un edificio público de carácter administrativo o bien era la sede de una agrupación religiosa o de otro tipo (Escrivá et al., 2016, 433). 
de Herrera, Sevilla (Fig. 3b) está decorada con una posible combinación de octógonos y círculos, sobre fondo blanco imitando el opus musivum (Fernández Díaz, 2016: 528-529, fig. 30). Más dudosa resulta la decoración de la Casa de la Exedra en Italica (Sevilla) (Fig. 3c) ya que, dado lo exiguo del fragmento conservado, se desconoce el desarrollo de la composición: quizás una circunferencia o semicircunferencia realizada con finísimos tallos vegetales, sobre fondo rojo, combinada con una figura poligonal, color burdeos sobre fondo blanco (Abad, 1982: 229).

Contamos con una doble cuadrícula, sobre fondo blanco, y trazada con plumas de pavo real, en la estancia del mosaico de Terpsícore de Valentia (López et al., 1994: 168 y 172, lám. 55) (Fig. 3d); los cuadrados resultantes que apoyan sobre el vértice están delimitados y tienen en su interior diversos elementos vegetales. Según Jiménez (2000: 32 ), los fragmentos hallados en el relleno de la actual plaza de Cisneros de Valencia remitirían a un techo de similares características y quizás elaborado por el mismo taller. De igual forma, se recurre a las plumas de pavo para elaborar la cuadrícula

b) oblicua que decora el techo hallado en la estancia 1 del Edificio de los Cinco Caños de Cauca, actual
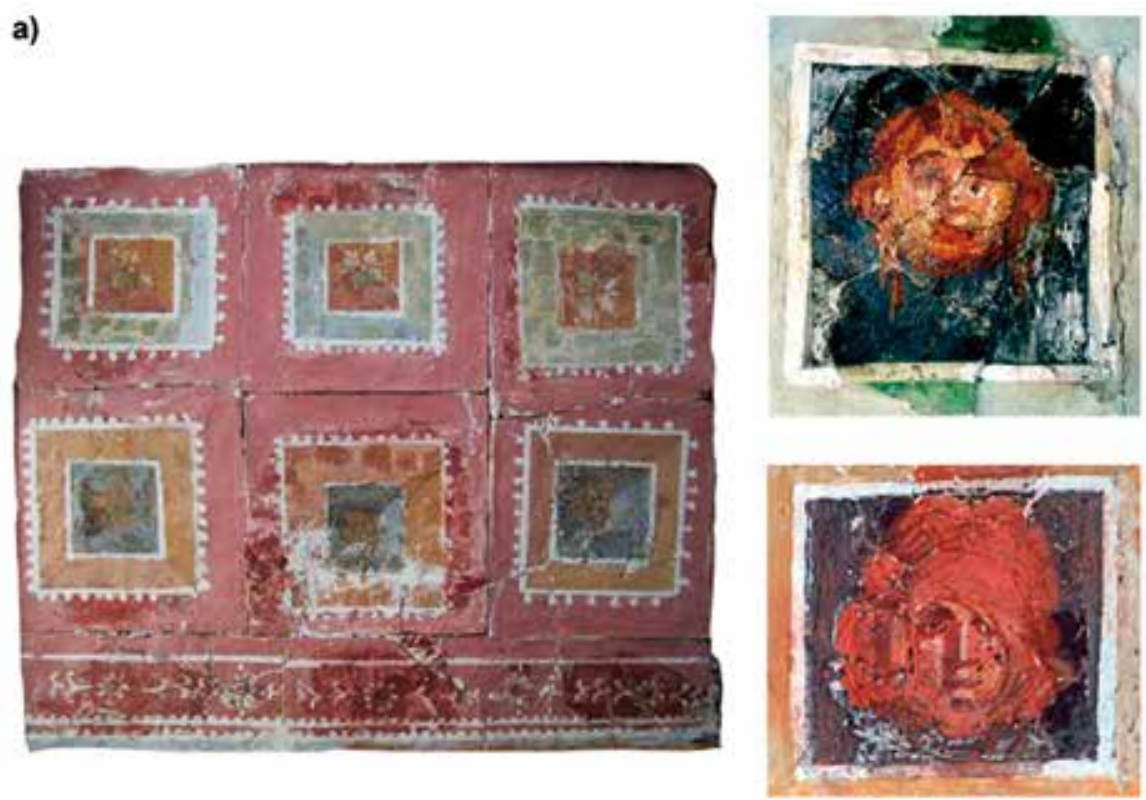

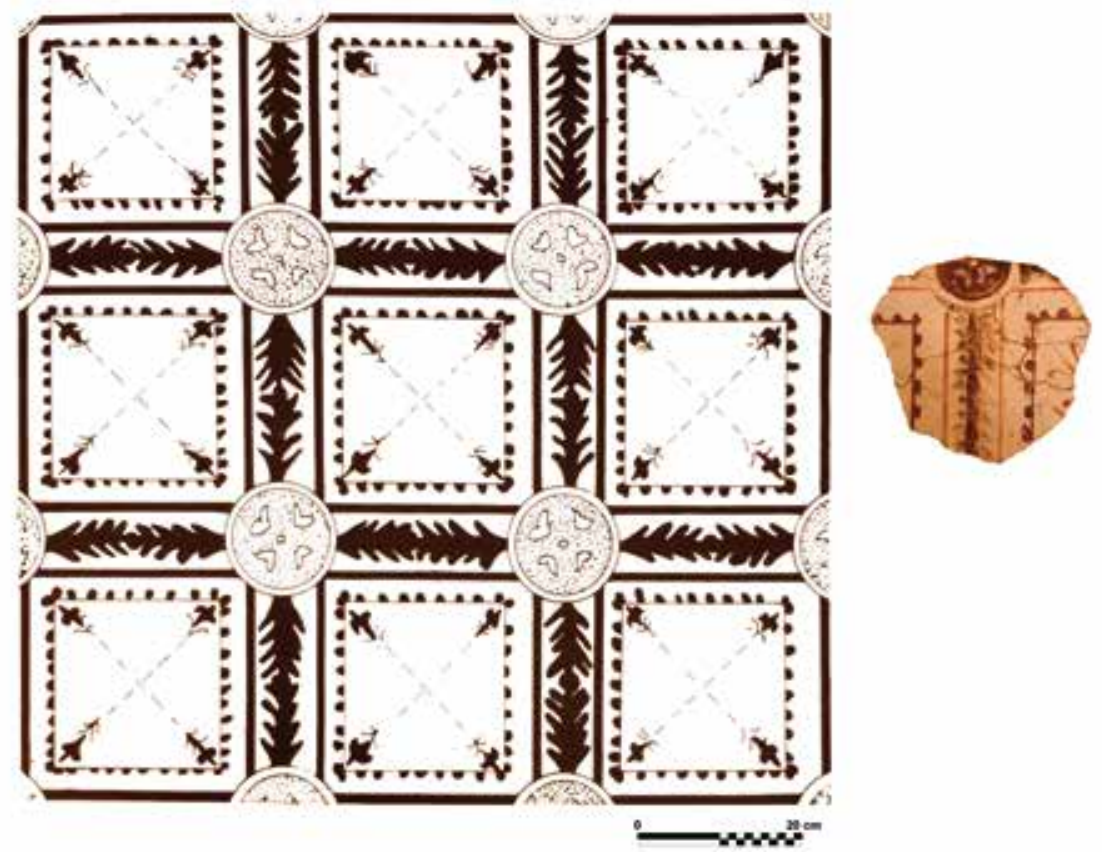

Fig. 2. Techos fechados en el s. II $d$. C. con sistema de relación continua basado en imitación de casetones: a) Casa del Sector 5 e de Ilici (Abad, 1982: 12, figs. 7 y 8); b) Estancias anteriores de la denominada Domus de Terpsicore en Valentia (según López et al., 1994: 157, lám. 50). 
a)

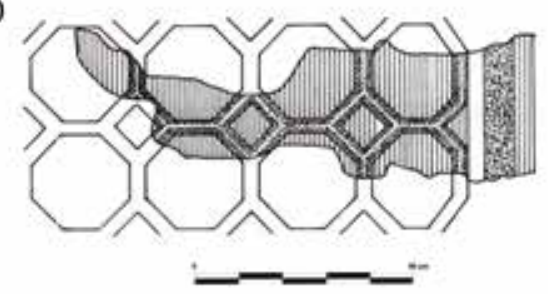

c)
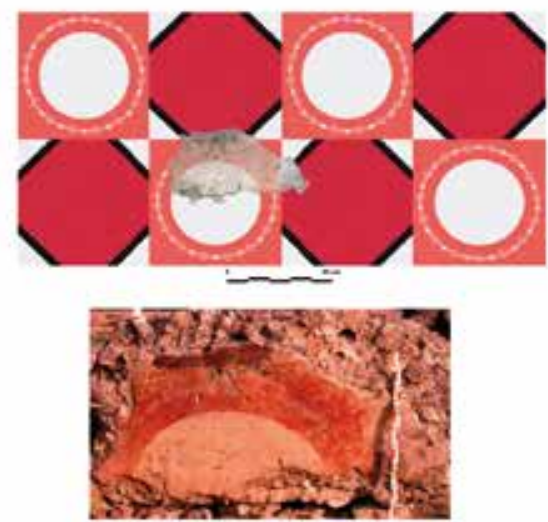

e)
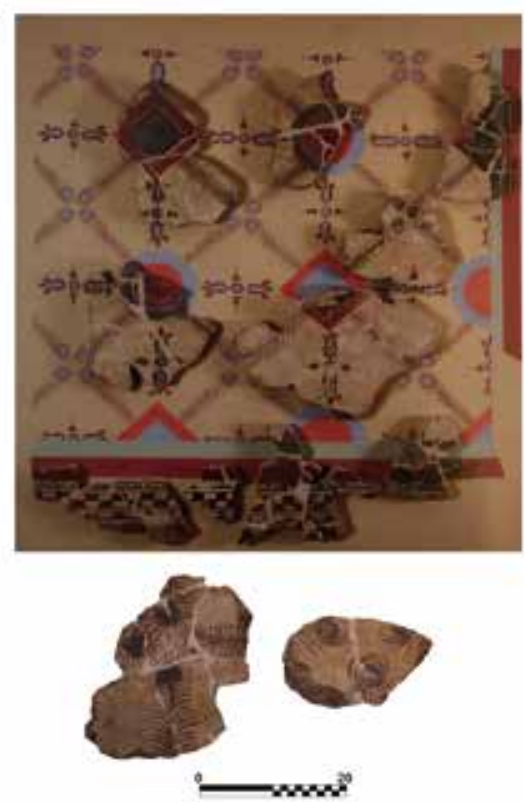

b)

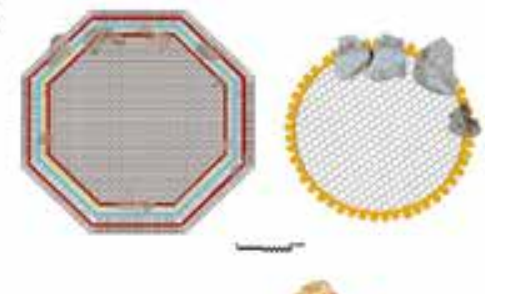

d)

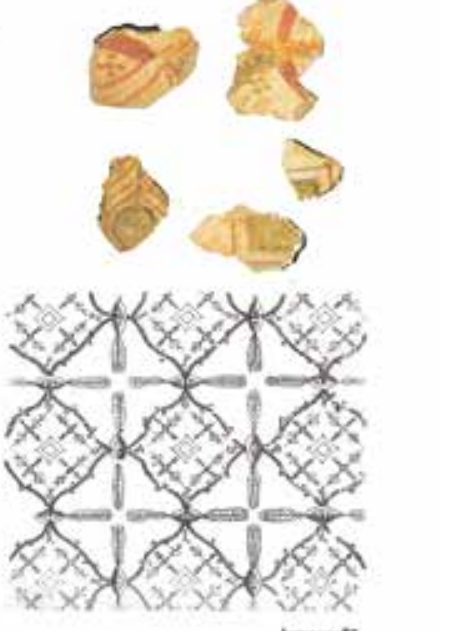

f)
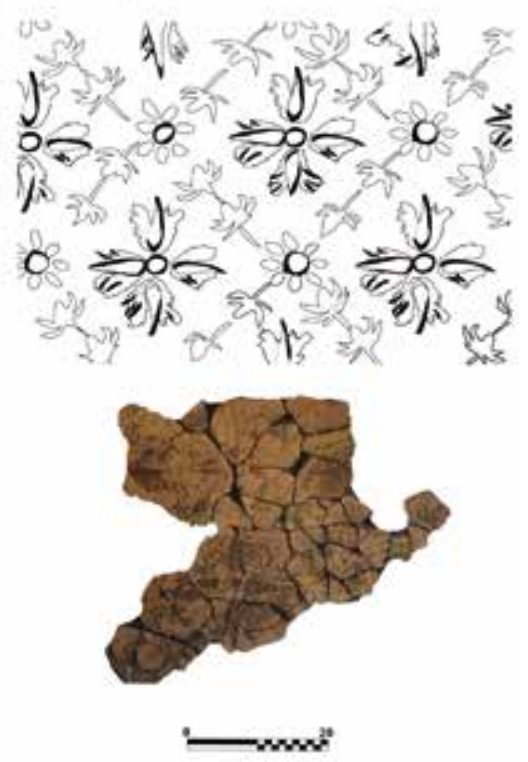

Fig. 3. Techos fechados en el s. II $d$. C. con sistema de relación continua con figuras geométricas derivadas de casetones: a) Tumba de Vildé (Abad, 1982: 188, fig. 431); b) bóveda del caldarium del conjunto termal de Herrera (a partir de Fernández Diaz, 2016: 528, fig. 30); c) Casa de la Exedra en Italica (Abad, 1982; digitalización de Fernández Díaz: 174, figs. 384-385); d) Estancia del mosaico de Terpsicore de la denominada Domus de Terpsicore de Valentia (a partir de López et al., 1994: 168, lám. 55); e) Estancia 1 del Edificio de los Cinco Caños de Cauca (Martín et al., 2020: 202, fig. 4); f) Viridarium de la Domus de las Columnas Rojas en Sisapo (Hevia et al., 2007: 473, figs. 4 y 5c).

Coca, Segovia (Fig. 3e). En este caso, en las intersecciones con la cuadrícula recta, más vegetalizada, hallamos de forma alterna cuadrados que apoyan sobre el vértice y círculos rojos y azules (Martín et al., 2020: 201-202, figs. 3-4). Finalmente, citamos el techo hallado en el viridarium de la Domus de las columnas rojas en Sisapo, Ciudad Real (Fig. 3f), decorado con una cuadrícula simple y oblicua, pero con líneas vegetalizadas rojas y verdes (Hevia et al., 2007).

De estos esquemas derivados de la imitación de casetones, pasamos a otros modelos, como el que decora el techo de la Habitación 2 de la Casa de G. Iulius Silvanus de Segobriga (Cuenca) (Fig. 4a), de finales del s. II, de composición ortogonal, sobre fondo blanco, con círculos secantes que parecen formar cuatro pétalos y determinan cuadrados cóncavos sobre el vértice, círculos rojos en los puntos de unión, líneas de cuadrícula oblicuas con respecto a las líneas del eje y cuadrados en la intersección, que alternan con los círculos de los puntos de unión. Similar, aunque sobre fondo amarillo y con los círculos azules, 


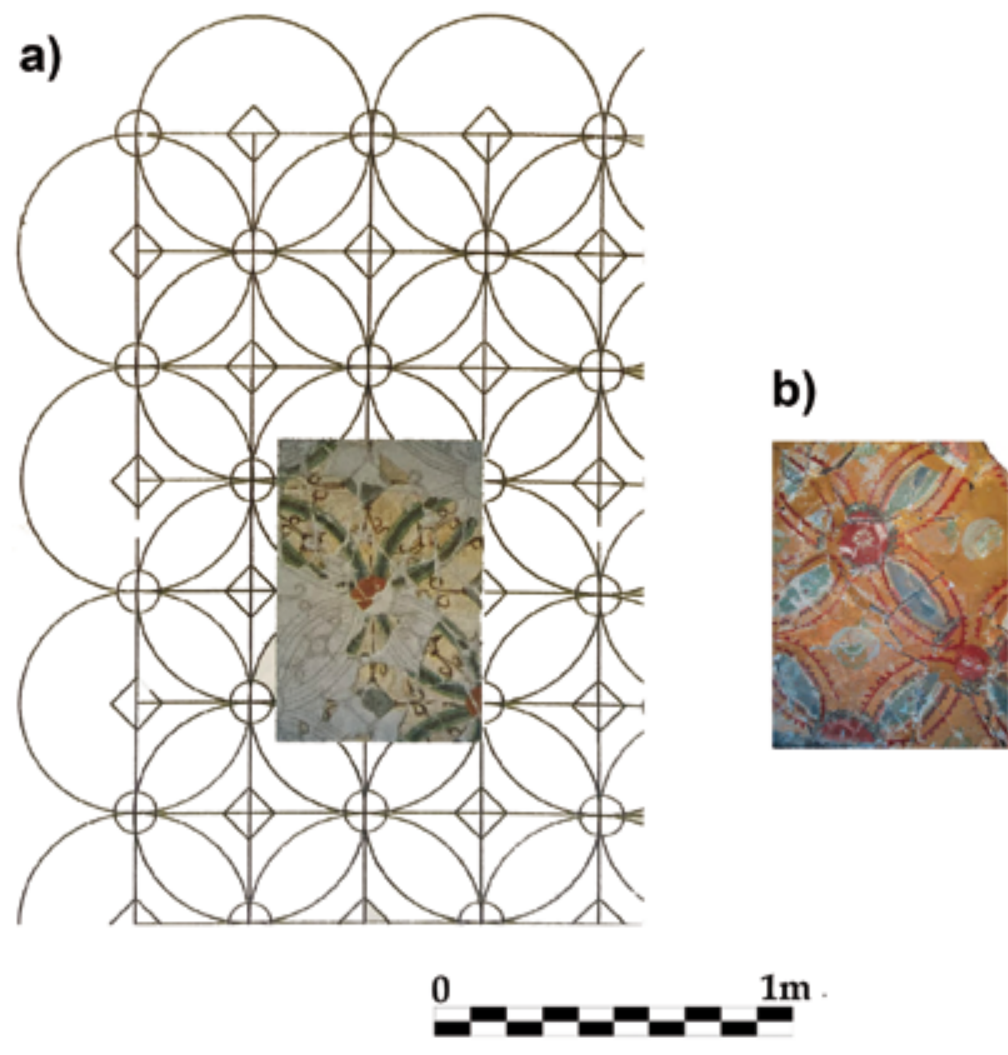

FIG. 4. Techos con otros modelos de relación continua: a) Habitación 2 de la Casa de G. Iulius Silvanus de Segobriga (Cebrián y Fernández Díaz, 2004: 141, lám. 8); b) Ilici (Cebrián y Fernández Díaz, 2004: 140, lám. 7).

es el techo de Ilici, Elche (Cebrián y Fernández, 2004a) (Fig. 4b).

En las centurias siguientes, el número de cubiertas decoradas con este esquema desciende considerablemente. Entre ellas, la cubierta de la Estancia LXII de la villa de El Ruedo en Almenidilla, Córdoba (Fig. 5a), de finales del s. III o principios del s. IV, sobre fondo blanco y con decoración vegetal que vuelve a recordar a un esquema de imitación de casetones; todas las líneas están vegetalizadas y en el interior de los casetones encontramos círculos decorados con complicadas flores cuadripétalas, que también interrumpen las líneas vegetalizadas (Cánovas, 2002).

El ejemplo hispano más tardío es la cubierta curva del baptisterio de la basílica paleocristiana de
Barcelona, del s. vi (Fig. 5b). La decoración consiste en una doble cuadrícula sobre fondo blanco, con grandes círculos en las intersecciones y círculos en su interior insertos en motivos estrellados; la cuadrícula oblicua, más vegetalizada, presenta un motivo cuadrado, injerido en un motivo estrellado (Albiol, 2013).

Para finalizar es preciso citar la decoración de la cubierta de Santa Eulalia de Bóveda, en Lugo. Los laterales, conservados in situ, presentan una composición sobre fondo blanco basada en una cuadrícula oblicua de filetes tratados como tallos vegetales decorados en su interior con distintos tipos de aves (Fig. 5c); en la parte central de la bóveda el esquema muestra, sobre fondo oscuro, una composición de octógonos irregulares secantes y adyacentes por el lado largo, que definen cuadrados y hexágonos oblongos (Abad, 1982: 151-152). Su cronología continúa siendo objeto de debate y oscila desde la tradicional del s. Iv hasta la más reciente del s. Ix, basada en el estudio de la arquitectura. A pesar de la similitud con algunas pinturas de las iglesias asturianas de los ss. Ix y x se constatan diferencias de los pigmentos, plenamente romanos en Santa Eulalia, con empleo de azul egipcio y rojo cinabrio, en tanto que estos pigmentos no aparecen en las iglesias del Reino de Asturias (Blanco-Rotea, 2009: 182-188).

\section{Sistemas de relación continua en techo y zona superior de la pared}

En este apartado nos centraremos en aquellas pinturas en las que este sistema compositivo se dispone en el sector superior de la pared y también ocupa la cubierta, creando una superficie continua 
a)
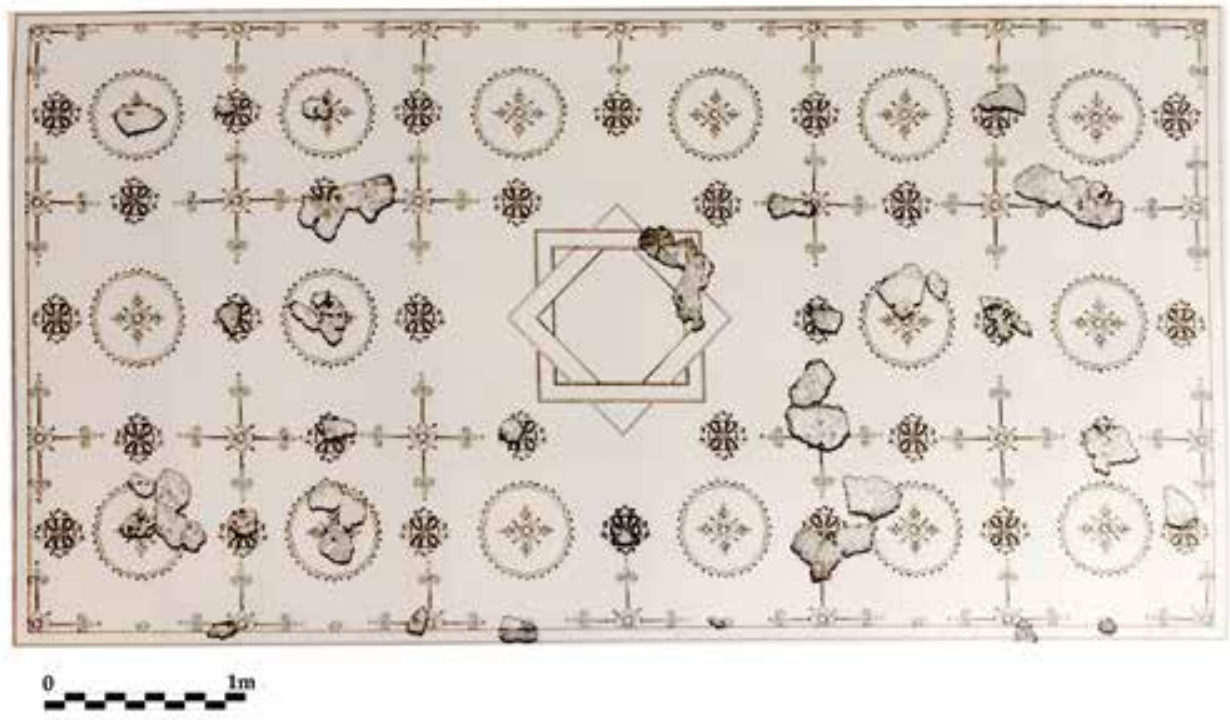

b)

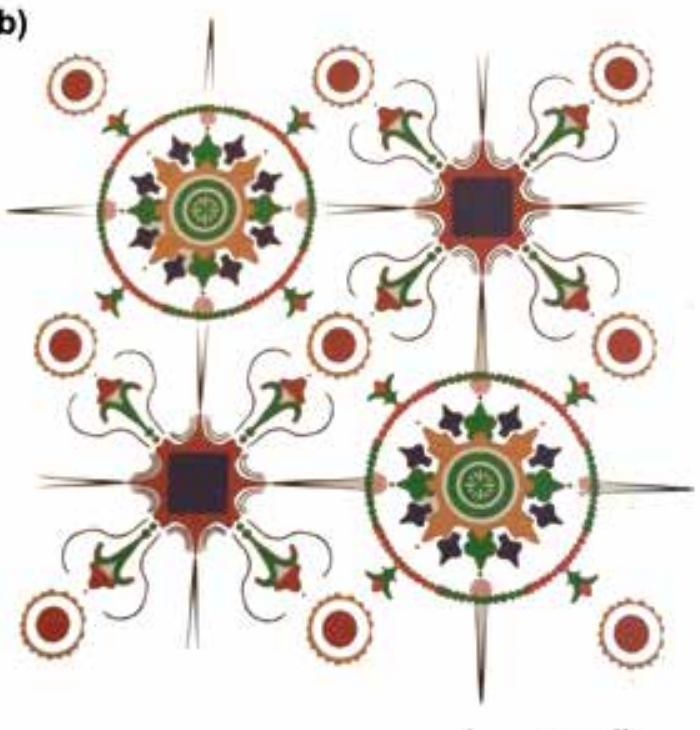

c)

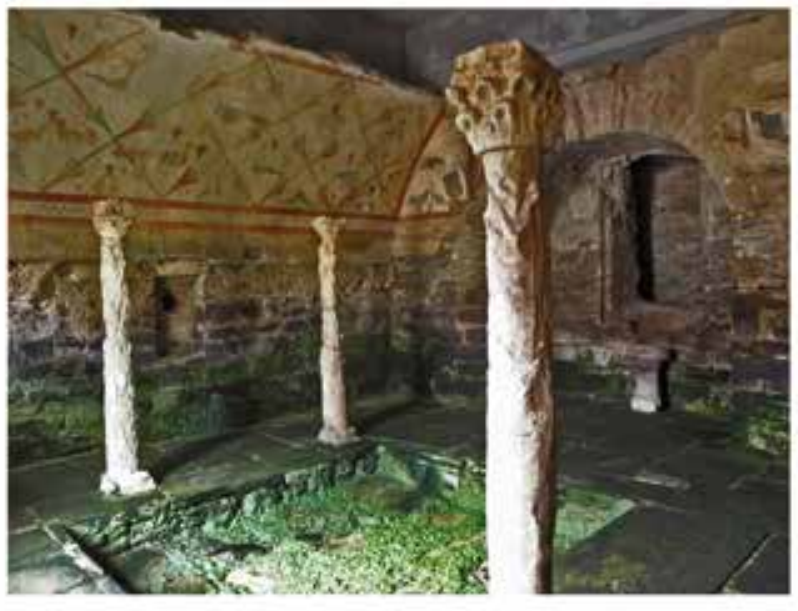

FIG. 5. Techos fechados entre los ss. III y VI (¿o LX?) con esquemas variados de relación continua: a) Estancia LXII de la Villa de El Ruedo (Cánovas, 2002: 102, fig. 125); b) Baptisterio de la basilica paleocristiana de Barcelona (Albiol, 2013: 172, fig. 9); c) Santa Eulalia de Bóveda (Wikimedia Commons contributors).

que, en ciertos casos, está separada por una cornisa de estuco.

En la segunda mitad del s. I d. C. se fechan dos conjuntos bilbilitanos, de similares características y realizados por el mismo taller: el procedente de las termas (Fig. 6a) consiste en una retícula de rectángulos, formados por bandas azules sobre

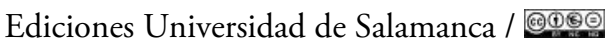

fondo rojo y decorados con roseta blanca central, que se extiende a la zona superior sin solución de continuidad. En la Casa del Larario, las bandas son verdes y los rectángulos lisos; en este caso sí existe una cornisa de estuco que interrumpe la decoración (Guiral y Martín-Bueno, 1996: 125-134, 355) (Fig. 6b). 
En la Estancia 11 del Edificio del Atrio del Cerro del Molinete en Cartagena, se halló el derrumbe de dos estancias del piso superior, en el que se exhumaron dos conjuntos pictóricos correspondientes a la zona alta de la pared y al techo. En el primer

a)

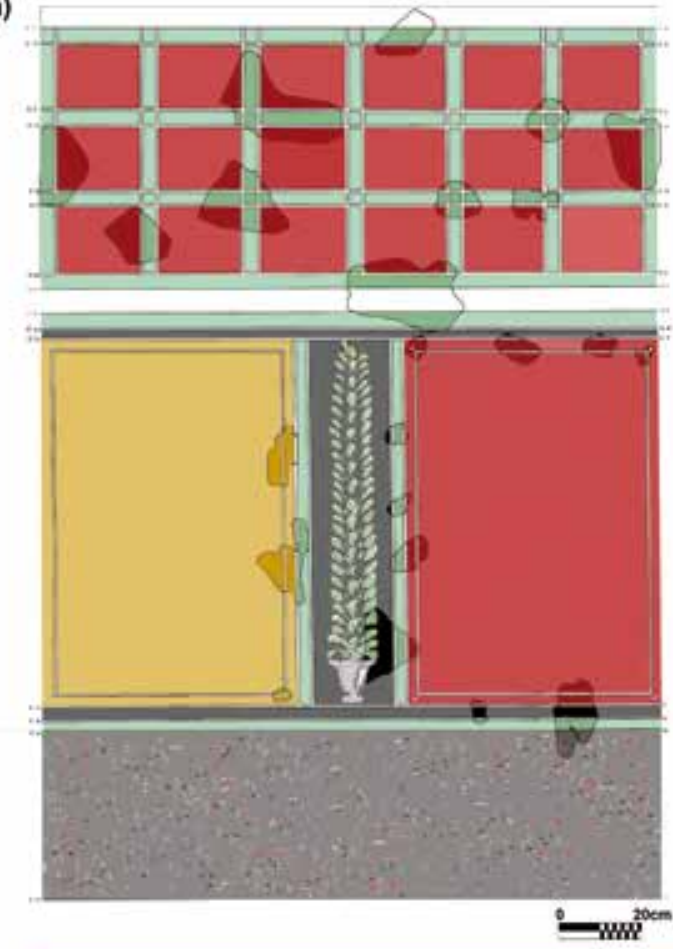

c)

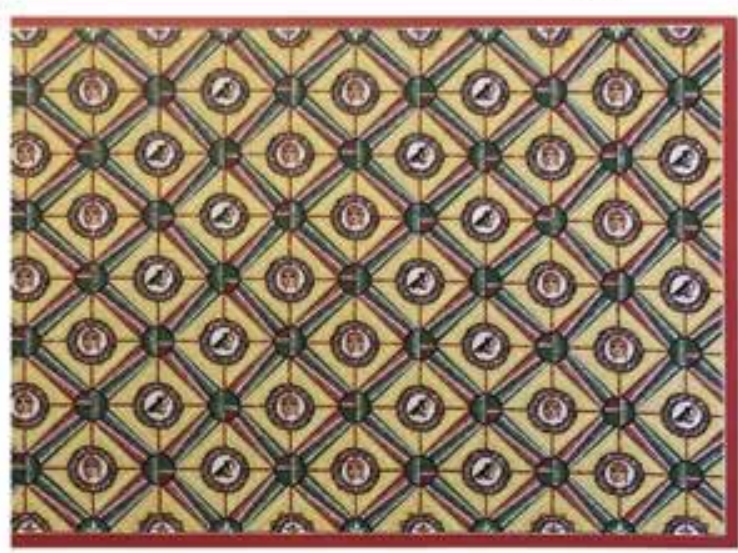

conjunto, la composición sobre fondo amarillo consiste en una doble cuadrícula recta y oblicua realizada con bandas denticuladas verdes y rojas, cuyo interior está decorado con pájaros, cabezas femeninas y florones (Fig. 6c). El segundo, también sobre

b)

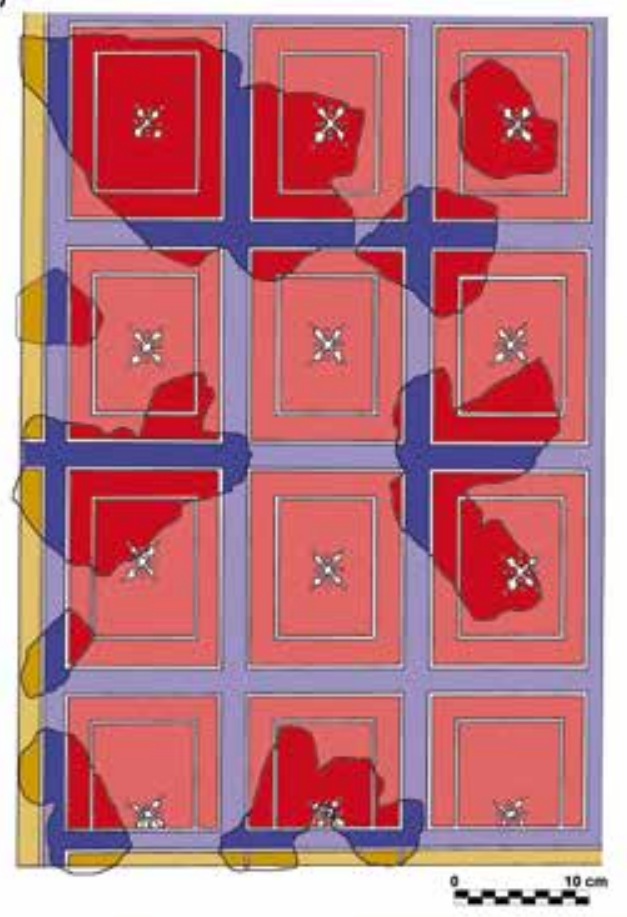

d)

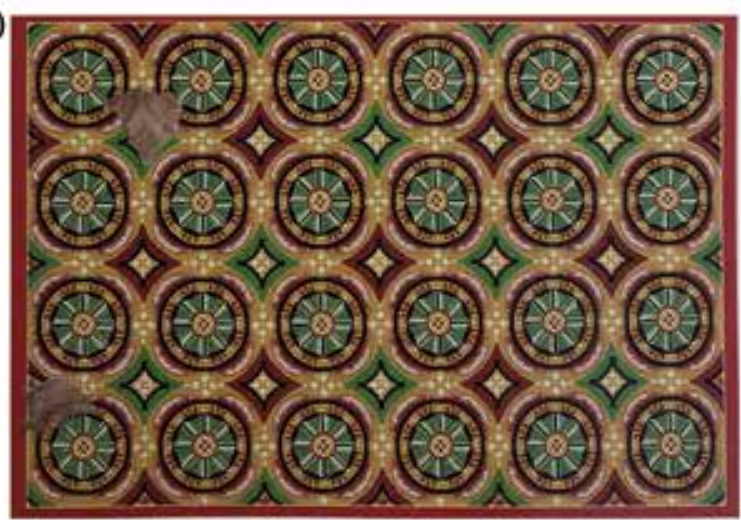

0

FIG. 6. Sistema de relación continua en techos y zona superior de la pared: a) hallado en las Termas de Bilbilis (a partir de Guiral y Martin-Bueno, 1996: 127, fig. 36); b) Casa del Larario de Bilbilis (a partir de Guiral y Martín-Bueno, 1996: 352, fig. 176); c-d) hallados en el derrumbe de las habitaciones superiores a la Estancia 11 del Edificio del Atrio (Fernández Diaz et al., 2014: Taf. CLVII, Abb. 6 y 7). 
fondo amarillo, muestra círculos secantes que delimitan cuadrados rojos y verdes, con lados cóncavos y apoyados sobre su vértice (Fernández Díaz et al., 2014: 479) (Fig. 6d).

\section{Sistemas de relación continua en la zona superior de la pared}

En las pinturas campanas los ejemplos no son muy numerosos, pero estos aumentan considerablemente en la Península Itálica y en las provincias, sobre todo durante el s. II, y es en este contexto en el que se integran las pinturas hispanas, donde existe cierta diversidad.

En un primer grupo, la zona media consiste en una alternancia de paneles e interpaneles decorados con candelabros y en él incluimos las pinturas bilbilitanas ya descritas -vid. supra- ${ }^{16}$.

En el s. II se fechan las pinturas de la Estancia $\mathrm{F}$ de la Casa de los Grifos de Complutum, Alcalá de Henares (Fig. 7a). La cuadrícula de la zona superior se presenta como un aparejo isódomo negro, con los rectángulos decorados con una roseta (Sánchez Montes, 2015: 64-65). De la misma fecha son las decoraciones de una domus excavada en Belchite, Zaragoza (Fig. 7b), con una doble retícula en rojo sobre fondo amarillo con una roseta en las intersecciones (Íñiguez y Rodríguez, 2020). En las pinturas de la habitación norte de la Domus de la Puerta Oriental de Lucentum, Alicante (Fig. 7c), de la primera mitad del s. II d. C., el sistema de relación continua se desarrolla sobre un fondo blanco y consiste en una serie de medallones en los que se insertan motivos tales como cabezas femeninas, pájaros, flores cuadripétalas y rosas o amapolas (Fernández Díaz, 2000-2001: 35-59, láms. 5-9; 2004: 343,

16 Posiblemente el sistema de relación continua hallado en las termas bilbilitanas corresponda en realidad a la zona superior y techo de la exhumada en el mismo lugar y, efectivamente, muestra una zona media basada en la alternancia de paneles e interpaneles (Guiral y Martín-Bueno, 1996: 111-125).
346) ${ }^{17}$. Del conjunto pictórico hallado en el Sondeo 39 del Cerro de El Molinete de Carthago Nova (Fig. 7d), del s. II d. C., se conservan algunos fragmentos con una cabeza femenina rodeada por una guirnalda vegetal bícroma, muy similar a las que decoran el sistema de relación continua de la Estancia 15 del Edificio del Atrio (Fernández Díaz, 2008: t. I, 242-243, lám. 40; t. II, 61 y 64, lám. 17) ${ }^{18}$. En la estancia del Sector II de la Villa de los Torrejones, en Yecla, Murcia (Fig. 7e), el esquema consiste en una doble cuadrícula, sobre fondo amarillo, con grandes círculos en la intersección de la cuadrícula recta, y pequeños círculos en las intersecciones de las dos cuadrículas, decorados los círculos con zancudas (Fernández Díaz, 1999: 68-71; 2004a: 343-346) ${ }^{19}$.

En un segundo grupo, la zona media de la pared se articula en paneles con imitaciones marmóreas separados por columnas. Por el momento, tan solo conocemos el conjunto procedente de la Habitación 2 de la Casa 4 de Graccurris, Alfaro, del s. II d. C., donde el esquema, sobre fondo blanco, consiste en cuadrículas dobles rectas y oblicuas con círculos alternos grandes y pequeños, en las intersecciones (Fig. 8). Es preciso señalar que la cuadrícula oblicua se halla vegetalizada, de forma que los círculos de menor tamaño están conectados con pétalos de cáliz, y, además, se ha documentado la presencia de una cabeza femenina en uno de los círculos rojos (Íñiguez et al., 2021).

Finalmente, se han documentado otros conjuntos de los que se desconoce la zona media de la pared. Así ocurre con las pinturas halladas en la Habitación 15 del Edificio del Atrio de Carthago Nova, Cartagena, y que, presumiblemente, decoraban la

17 La autora mantiene la duda de su pertenencia al techo o a la zona alta de la pared, pero expone con claridad que los reversos de los fragmentos carecen de las características improntas de las cańas que conforman la estructura de las cubiertas, por lo tanto, parece plausible pensar que decoraban la zona superior.

18 Estos fragmentos fueron hallados junto con otros correspondientes a una zona media dividida en paneles e interpaneles, aunque no podemos asegurar que se trate del mismo conjunto.

19 Agradecemos a A. Fernández Díaz la ayuda prestada para la comprensión de este conjunto.

Zephyrus, LXXXVIII, julio-diciembre 2021, 163-189 
estancia ubicada encima. Consiste en un esquema ortogonal de círculos secantes, rojos y azules, que parecen formar cuadrifolios y que crean cuadrados cóncavos con motivos florales y cabezas femeninas en los círculos interiores (Fig. 9a). Se fechan en época antonina (Fernández Díaz et al., 2014: 479-481). También debemos incluir aquí la zona superior hallada en la Estancia 1 de la porticus post scaenam del teatro romano de la misma localidad (Fig. 9b), datada a mediados del $s$. II. Su sistema en red, sobre fondo blanco, se basa en círculos tangentes con medallones en su interior -con representaciones vegetales y figuras zoomorfas- y con pequeños círculos secantes entre ellos (Fernández Díaz y Castillo, 2020: 108-112, figs. 14-17).

\section{Sistemas de relación continua en la zona media}

Las pinturas en las que este sistema ocupa la zona media, generalmente sobre zócalo de imitación marmórea, rompen con los esquemas tripartitos o paratácticos que caracterizan la pintura
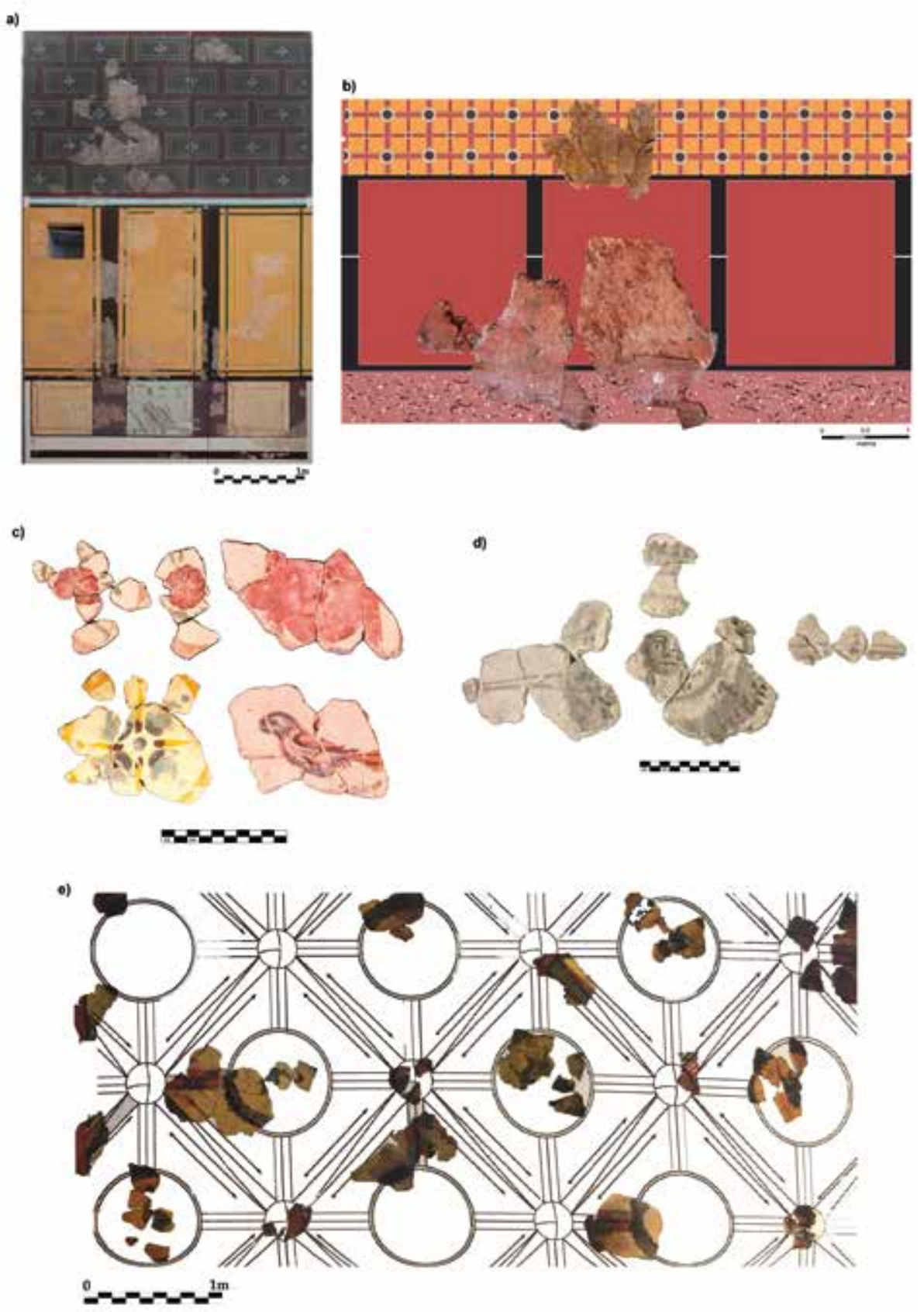

Fig. 7. Sistemas de relación continua en la zona superior de la pared sobre una zona media basada en la alternancia de paneles e interpaneles: a) Estancia F de la Casa de los Grifos de Complutum (Sánchez Montes, 2015: 65, fig. 19); b) Espacio 5 de la Domus de Belchite (infografía P. Rodriguez); c) habitación norte de la Domus de la Puerta Oriental de Lucentum (Fernández Diaz, 2000-2001: 37-40, láms. 5-8); d) hallazgo en el Sondeo 39 del Cerro de El Molinete de Carthago Nova (Fernández Díaz, 2008: 243, lám. 40); e) Sector II de la Villa de los Torrejones (Fernández Díaz, 2004a: 344 , lám. 4). 


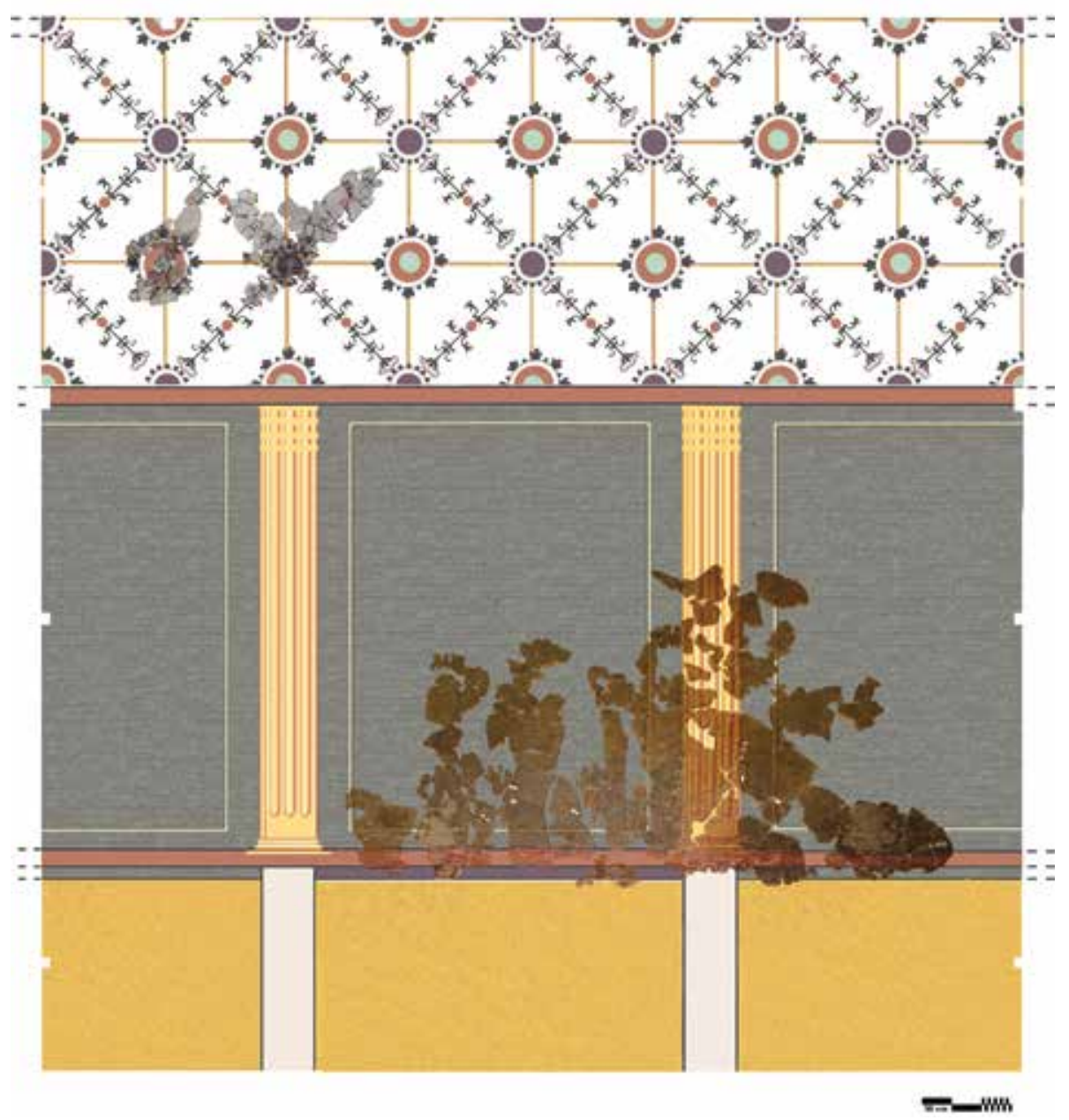

Fig. 8. Sistemas de relación continua en la zona superior de la pared sobre una zona media basada en paneles con imitaciones marmóreas y separados por columnas, en Graccurris (infografia L. Íñiguez).

romana. Son menores en número, fenómeno que no solo ocurre en la Península Ibérica ya que en la pintura campana solo se conservan seis estancias con este tipo de decoración, todas ellas fechadas en los márgenes cronológicos del iv estilo.

En el Cubículo i de la Casa degli Amorini Dorati -vi 16, 7- el zócalo está decorado con imitación pintada de crustae marmóreas (Fig. 11a); en la zona media, de fondo amarillo, se dispone una red de hexágonos y cuadrados flanqueados por triángulos, con motivos florales centrales (Seiler, 1992: 49-51, figs. 310-333). En el Oecus 28 de la Casa dei Capitelli Colorati (vir 4, 31.51), el zócalo también está decorado con imitaciones marmóreas y la zona media, de fondo rojo, con complejos motivos florales que forman una retícula de losanges -PPM VI, 1071, figs. 108 y $110-$ El Triclinio 17 de la Casa di Severus-vin 2, 29-30- presenta un zócalo negro, muy perdido, y en la zona media se dispone una red de meandros con esvásticas y cuadrados rojos, sobre fondo amarillo -PPM VIII, 260-261, figs. 37-40-. En la trastienda de la $T a-$ berna-V 1, 30-31-, sobre un zócalo amarillo el sistema de relación continua, amarillo sobre fondo rojo, consiste en una alternancia regular de rosetas inscritas en círculos y motivos florales - PPM III, 626-627, figs. 2-4-. Las paredes de la Taberna -VII 14,1-se conocen por antiguas descripciones, que indican que estaban pintadas como un tapiz con una greca continua sobre fondo amarillo -PPM VII, 660-. Finalmente, en la Exedra 9 de la Villa de Varano en Stabia, el zócalo es rojo, dividido en compartimentos decorados con motivos figurados; la zona media, de fondo blanco, está ornamentada con una retícula de cuadrados que apoyan sobre el vértice, con distintos motivos vegetales, animales y figurados en su interior (Cerulli et al., 1993: t. II, 258, n. ${ }^{0}$ 495).

A pesar de que no es un tipo decorativo muy común, en la Península Itálica se constatan otros ejemplos. En el Cubículo 34 de la Villa de Settefinestre, fechado en los márgenes cronológicos del IV estilo, sobre un zócalo de fondo negro, la zona media, de fondo rojo, está decorada con una retícula de 
cuadrados formados por motivos vegetales, con un pájaro central (Cavari, 1985: 231-234).

Los fragmentos hallados en el área del templo Gallet de Aquileia permiten restituir una pared con zócalo de imitaciones marmóreas y zona media, de fondo blanco, decorada con círculos secantes, verdes y rojos alternativamente, con motivos florales en el centro. Se datan entre los ss. II y III d. C. (Provenzale, 2005: 473-477, figs. 1-4, dis. 1). La Estancia R de la Domus del Palacio Diotallevi en Rímini, de época adriánea, presentaba un zócalo rojo y la zona media con círculos secantes sobre fondo blanco (Scagliarini, 1985-1987: 580; Fontemaggi et al., 2001: 274, fig. 2). La cuarta aula del Capitolium flavio de Brescia conserva la pintura in situ y el sistema de relación continua, compuesto por rombos y octógonos, ocupa la zona media y superior de la pared; se data en un momento posterior a época flavia ya que corresponde a una reforma del edificio (Mariani, 2013). Por último, en una de las estancias superiores de la casa del barrio de San Teodoro en Pola, el zócalo está decorado con imitaciones marmóreas y el esquema se basa en la repetición de cuadrados con motivo floral en el centro. Se fecha a inicios del s. II d. C. (Starac, 2012: 248-249).

Este sistema decorativo perdura hasta, al menos, el s. III d. C. tal y como se observa en la Estancia 7 de la Insula del Aquila de Ostia, en la que sobre un
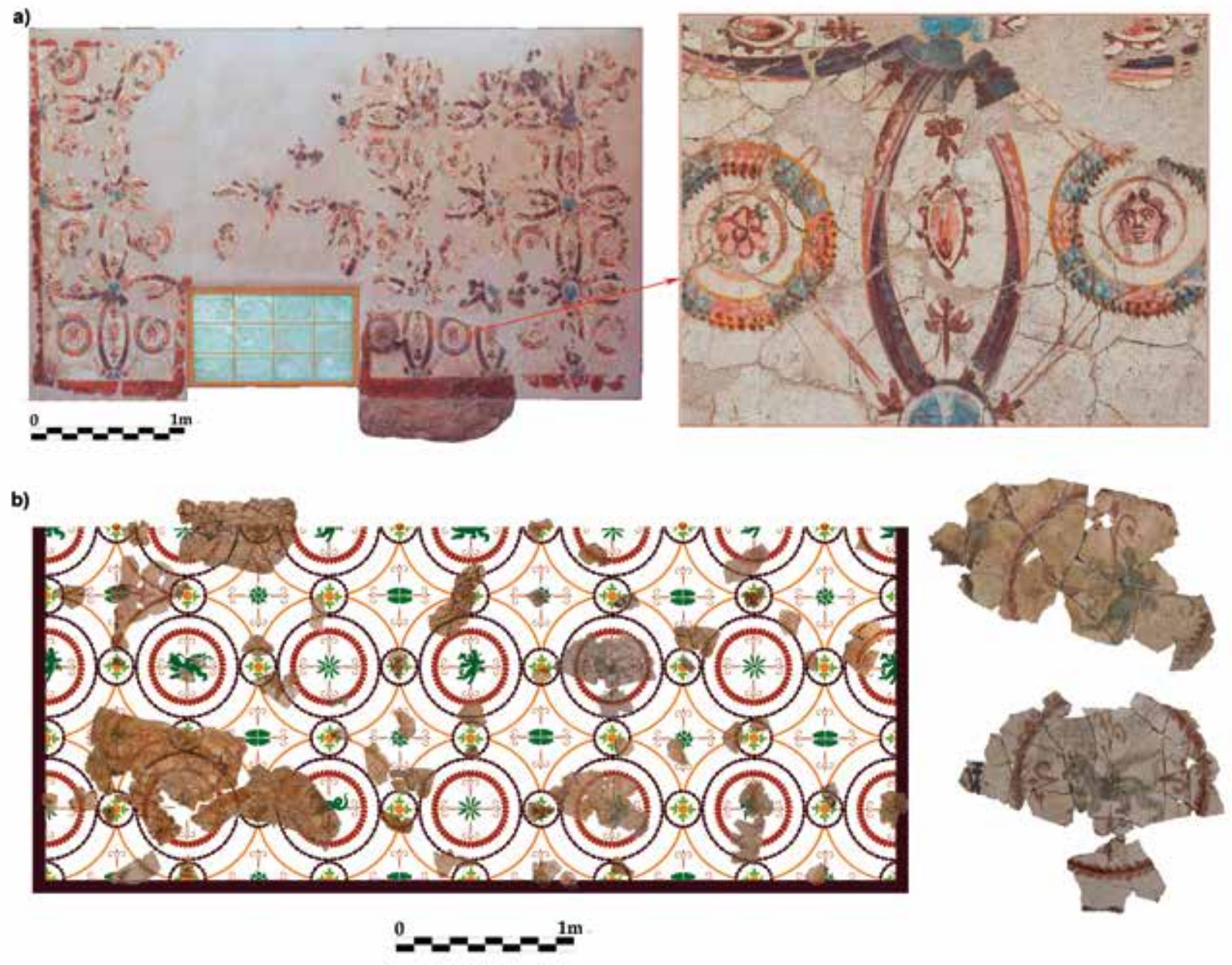

Fig. 9. Sistemas de relación continua en la zona superior de la pared para los que se desconoce la zona media: a) Habitación 15 del Edificio del Atrio de Carthago Nova (Fernández Díaz et al., 2014: Taf. CII, Abb. 10c); b) Estancia 1 de la porticus post scaenam del teatro romano de Carthago Nova (infografia de G. Castillo). 


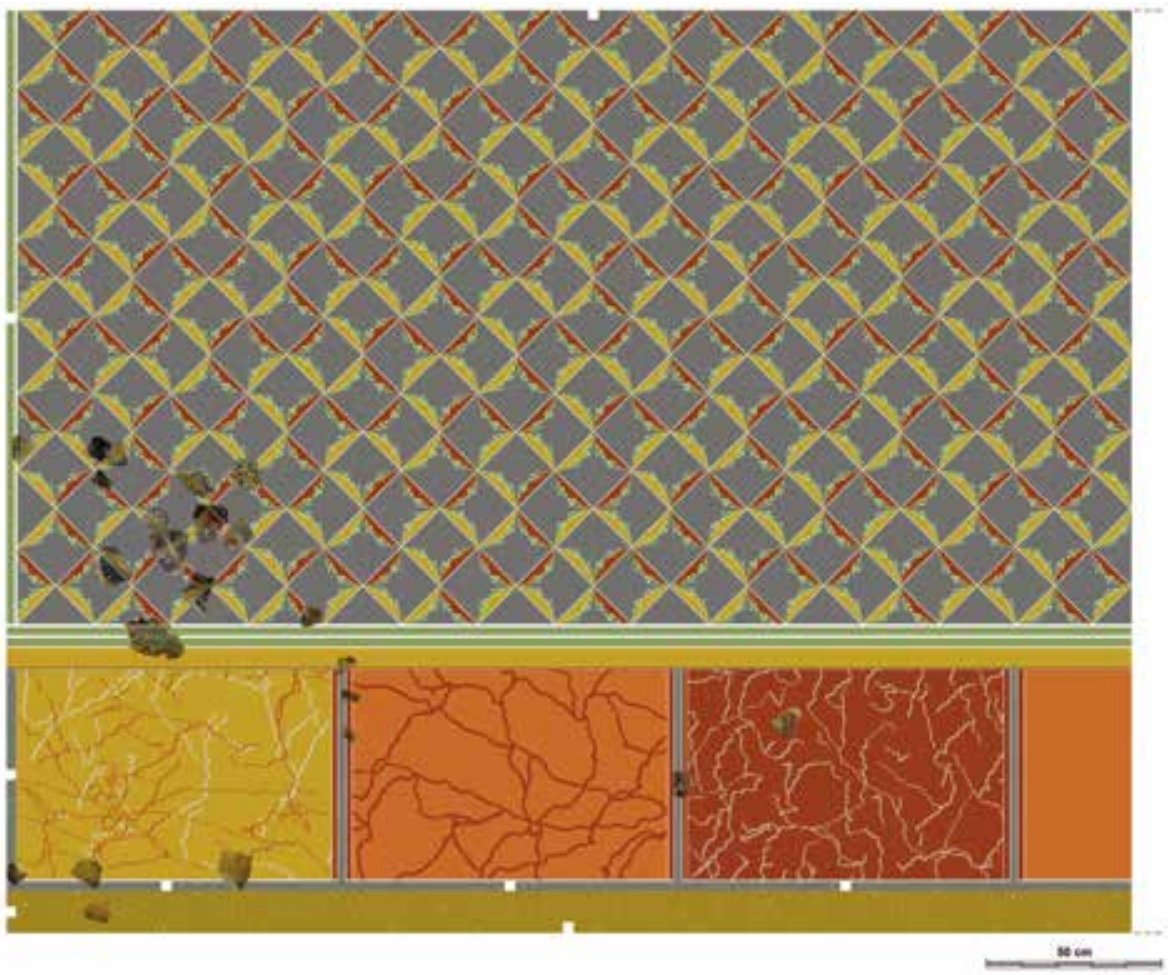

Fig. 10. Sistema de relación continua en la zona media: hallazgo en la cl Dormer de Huesca (Osca) (infografia de A. Blanco).
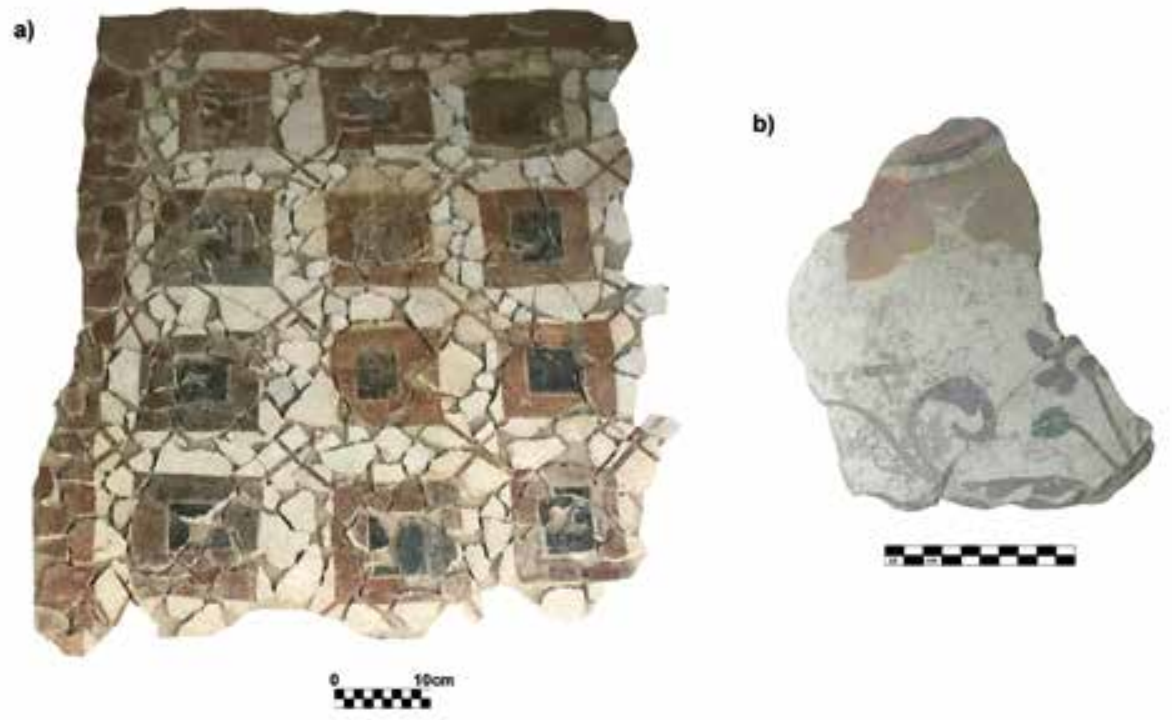

Fig. 11. Sistemas de relación continua para los que desconocemos si ocupaban el techo, la zona superior o ambas secciones: a) Andelos (Mezquiriz, 2009: 97); b) Villa de Cabriana (imagen de L. Íniguez). alto zócalo de imitaciones marmóreas se dispone un sistema geométrico consistente en filas simétricas de círculos, en los que se insertan cuadrados de lados cóncavos (Joyce, 1981: 45, fig. 41; Falzone, 2007: 144-146, figs. 92-93). También del s. III d. C., la antecámara del cubículo de la denominada 'Villa Grande', bajo la basílica de S. Sebastián de Roma (Fig. 11b), muestra un zócalo con imitaciones de opus sectile y la zona media con una malla de cuadrados que apoyan sobre el vértice, con flores estilizadas en el centro; Taccalite (2004: 409410, tav. 4) lo interpreta como la representación de un alto cancel que cierra un jardín.

En el mundo provincial son muy escasas, por el momento, las pinturas en las que este esquema decorativo ocupa la zona media. Solamente en Thillay, Francia, se representa un auténtico tapiz verde profusamente decorado y bordeado por flecos -vid. supra- (Groetembril y Vermeersch, 2017: 103-107, figs. 1011).

Por el momento, las únicas pinturas hispanas con este esquema proceden de la cl Dormer de 
Osca, Huesca, datadas a finales del s. I d. C. Sobre un zócalo decorado imitación de un sectile parietal, se dispone una composición sobre fondo negro, consistente en filetes azules paralelos dispuestos en diagonal, que se entrecruzan creando una retícula de cuadrados apoyados sobre uno de sus ángulos. Estas líneas diagonales están recorridas por un trazo serpentiforme que, al unirse con uno de los lados de los cuadrados, crea un segmento de círculo, pintado alternativamente en rojo y amarillo. Del cruce de las líneas azules que forman los ángulos del cuadrado, parten tallos vegetales blancos, que se adaptan al segmento de círculo, en cuyo centro forman un ramillete de hojas de color verde. Quizás lo más curioso de esta decoración es la posición diagonal de los filetes que articulan la decoración y sobre todo los elementos vegetales que se enroscan sobre estos (Fig. 10), lo cual nos permite hipotetizar sobre la posibilidad de la imitación pintada y muy libre de un cancel o valla de jardín (Guiral et al., 2018: 222-227).

\section{Sistemas de relación continua de adscripción indeterminada}

Existe un grupo de conjuntos pictóricos hispanos cuya adscripción a una zona u otra de la pared resulta difícil debido al escaso número de fragmentos conservados y/o a la carencia de las capas de mortero con impronta del sistema de sujeción que son indicio de su pertenencia a pared o techo.

Comenzaremos este elenco por aquellas decoraciones en las que desconocemos si ocupaban exclusivamente el techo, si se disponían solamente en la zona superior o si se extendían por ambos sectores. Es el caso de las pinturas de la Domus de la Fortuna en Carthago Nova que no conservan el sistema de sujeción. El esquema consiste en círculos elaborados con guirnaldas quizás decorados en su interior con cabezas masculinas y plumas de pavo. Se adscribe a la primera mitad del s. II d. C. (Fernández Díaz, 2004: 344; 2008: 268-270). También de Carthago Nova proceden las pinturas halladas en el pasillo del peristilo de la casa hallada en la c/ Duque 37. La composición, sobre el fondo blanco, se articula en una serie de octógonos irregulares y secantes,

Ediciones Universidad de Salamanca / 요 creando cuadrados y hexágonos oblongos que, según los autores, se disponían en una banda corrida y que probablemente correspondía a la zona media de la pared ${ }^{20}$. La datación propuesta oscila entre finales del s. I y mediados del s. II d. C. (Suárez y Fernández Díaz, 2006: 81-82, 103 y 106).

Los fragmentos hallados en la Casa de las Pinturas de Andelos, Mendigorría, han permitido recomponer una composición sobre fondo blanco basada en octógonos irregulares secantes y adyacentes que determinan, a través de filetes rojos, hexágonos oblongos y dobles cuadrados rojos y verdes. Aunque en el estudio de Mezquíriz (2009: 96-97) no se especifica su adscripción y tampoco se menciona el sistema de sujeción, el hecho de haber exhumando en la misma estancia el zócalo con imitaciones marmóreas y la zona media articulada en paneles rojos con filetes amarillos de encuadramiento interior y paneles amarillos con amplios filetes triples permite pensar que decoraría la zona superior y/o el techo de la estancia. La presencia de filetes de encuadramiento con lengüetas y, sobre todo, de ángulos rellenos de color en los amplios filetes triples (Guiral, 2018: 131) permite datar la decoración en el s. II d. C. (Fig. 11a).

Finalmente, traemos a colación el tercero de los cuatro conjuntos en los que Filloy et al. (1992) clasificaron los fragmentos exhumados en el fondo de la cisterna del peristilo y de un estanque contiguo en la Villa de Cabriana, en Comunión, Álava, asociados a materiales de finales del s. I y principios del s. II d. C. Uno de los fragmentos que los autores (Filloy et al., 1992: 111-112), erróneamente, sitúan en el zócalo con una circunferencia sobre fondo blanco, decorada con elementos vegetales, en realidad parece pertenecer a un sistema de relación continua muy similar al hallado en Graccurris - vid. apartado 4- (Fig. 11b). Tras la revisión del material ${ }^{21} \mathrm{y}$

20 Los autores no justifican la pertenencia a la zona media de la pared, por lo que se ha considerado oportuno incluir estas pinturas en este apartado.

${ }_{21}$ Agradecemos al Museo de Arqueología de Álava, donde están depositados los materiales de la Villa de Cabriana y de Veleia, el permiso para su estudio así como su amabilidad y disposición, especialmente a la técnico responsable del museo, J. Agirre.

Zephyrus, LXXXVIII, julio-diciembre 2021, 163-189 
habiendo comprobado que no se conserva el sistema de sujeción, apostamos por su posición en la zona superior y/o techo de la estancia ya que, de la misma decoración, sí se conserva el zócalo decorado con elementos vegetales y una zona media con paneles rojos encuadrados interiormente por amplios filetes triples $y$ filetes simples con puntos en diagonal en los ángulos y lengüetas.

Un segundo grupo lo conforman aquellas decoraciones fragmentarias de las que se ignora si ocupaban solo la zona superior o también la zona media. De los cuatro conjuntos ya citados de la Villa de Cabriana nos interesan ahora los dos primeros, interpretados como dos tipos de techos articulados en un sistema de relación continua compuesto por casetones sobre fondo blanco. En el primero (Fig. 12a), los casetones encerraban circunferencias decoradas similares a las vistas en Graccurris y en el segundo un aparejo se decora con una suerte de aspa con elementos vegetales (Fig. 12b). Tras la revisión de los materiales, hemos podido comprobar la imposibilidad de que decorasen techos ya que no presentan el característico reverso con las improntas de los cañizos, sino las trazas en negativo de las incisiones en forma de espiga, sistema de sujeción característico de las pinturas parietales. Planteamos la hipótesis, por tanto, de que se trate de dos conjuntos que decoraban la zona superior o media de sus respectivas paredes.

Las pinturas emeritenses procedentes del centro de culto metróaco pudieron ocupar la totalidad de la zona media ya que, según Heras (2011: 31-32), apoyan sobre un zócalo con imitaciones marmóreas; sin embargo, estas imitaciones ocupan también la parte mediana del muro por lo que no sería extraño que se ubicaran en la zona superior. La decoración

Ediciones Universidad de Salamanca / 용

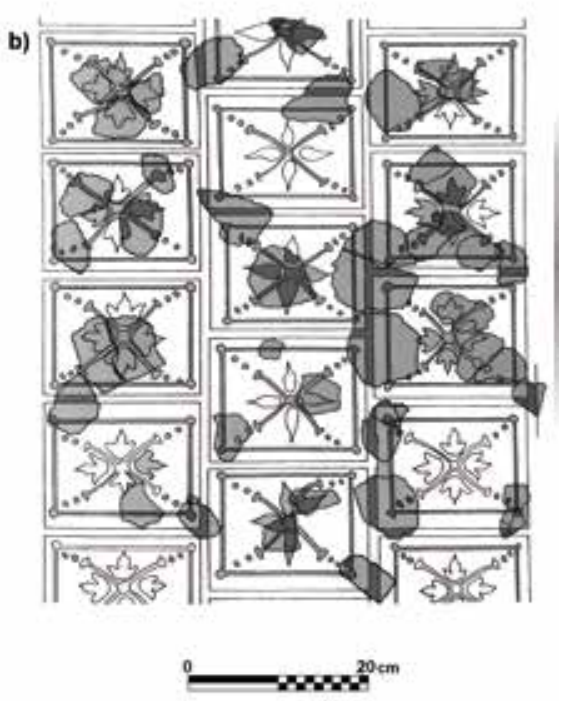
continua para los que desconocemos si ocupaban la zona superior
Villa de Cabriana (Filloy et al., 1992: 109-112).

se resuelve con hexágonos y cuadrados que encierran elementos florales en su interior (Fig. 13). El edificio se fecha entre mediados y finales del s. IV.

El tercer y último grupo lo forman aquellas decoraciones en las que ha sido imposible siquiera hipotetizar su ubicación. Como veremos, para muchas de ellas las descripciones antiguas y en otras la inexistencia de fragmentos representativos del propio sistema de relación continua, de otros sectores de la pared y, por supuesto, de las improntas en el mortero hacen imposible cualquier intento de ubicación.

Del vestíbulo del Sector J -Recinto 1- de Veleia, Iruña de Oca, Vitoria, posiblemente del s. II d. C., provienen varios fragmentos que remiten a un esquema en el que, sobre fondo blanco, se articulan casetones formando una cuadrícula; en cada intersección se dispone un motivo floral esquemático y en el interior de cada casetón un círculo vegetalizado con trifolios. Según Filloy et al. (1992: 108, fig. 2.2), debía decorar el techo de una estancia, pero lo cierto es que no hay ningún argumento en su descripción que avale esta tesis. Lo interesante es que guarda también grandes similitudes con los esquemas de Graccurris y con dos de los conjuntos procedentes de la Villa de Cabriana-vid. supra-. 
FIG. 13. Sistemas de relación continua para los que desconocemos si ocupaban la zona superior o la zona media: centro de culto metróaco de Emerita (Heras, 2011: 32).

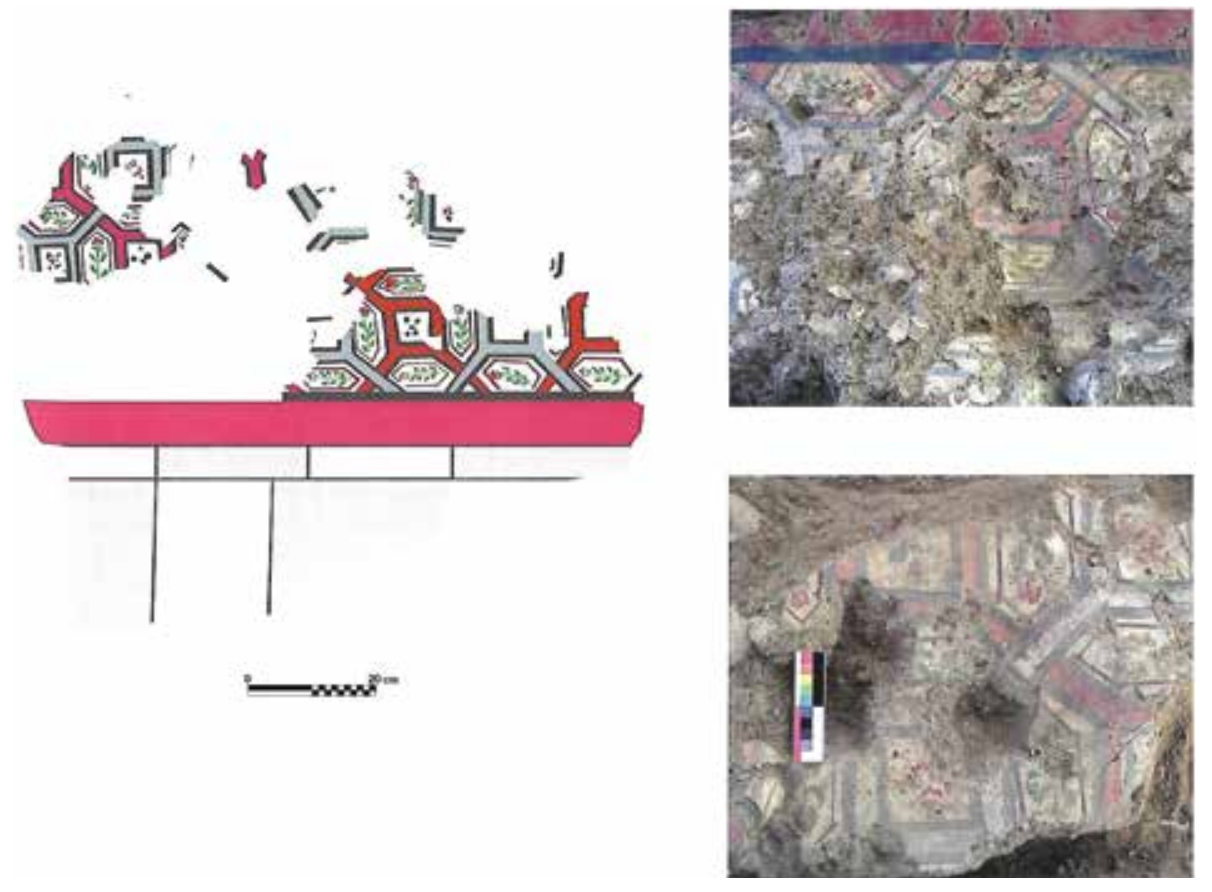

Otro posible conjunto pictórico, de características parecidas, procede del acceso al frigidarium de las Termas de Herrera, en Sevilla, datado a finales del s. II d. C., del que tan solo se han conservado escasos fragmentos de un círculo vegetalizado sin adscripción concreta a techo o pared (Fernández Díaz, 2016a: 526-527, fig. 28).

De la ciudad de Lugo, de la Rua Nova, procede una placa pictórica restaurada, en la que sobre fondo blanco se dispone un entramado de octógonos yuxtapuestos, con espacios cuadrados entre ellos, pintados en tonos ocres rojos y amarillos (González, 2005: 79-80).

Por último, es preciso citar algunos casos testimoniales recopilados por Abad. Algunos fragmentos de Italica, Sevilla, remiten a una composición sobre fondo blanco con octógonos irregulares adyacentes, de color verde, y con motivos vegetales en su interior, que definen cuadrados que apoyan sobre el vértice. Se fecha en torno a mediados del s. II d. C. (Abad, 1982: t. I, 218-219). El segundo proviene de la Casa de Taracena en Clunia, Burgos, de la Habitación 58, cuyos fragmentos remiten a

Ediciones Universidad de Salamanca / 요요 un esquema sobre fondo blanco articulado en octógonos irregulares secantes y adyacentes, que definen cuadrados, con decoración vegetal en su interior, y hexágonos oblongos; se fecha en el s. II d. C. avanzado (Abad, 1982: t. I, 97-98). Por último, citamos el dudoso ejemplo de Centcelles, Tarragona, conocido por la descripción de Schlunk, quien apunta que en la ventana de la cámara de debajo de la cúpula existen "... motivos de casetones formados por grandes círculos tangenciales sobre fondo azul oscuro. Los círculos, ordenados alrededor de un panel azul oscuro con una roseta de ocho hojas, están rodeados por anillos de color amarillo, marrón y rojo...", quizás del s. IV d. C. (Abad, 1982: t. I, 250).

\section{Conclusiones}

A través de las descripciones, ha quedado patente la gran variedad de esquemas de relación continua existentes en la pintura hispana.

En relación a la cronología, la decoración más antigua es el techo del oecus triclinar de la Casa de los Delfines de Celsa, datada en torno al 25-35 d. C. y, si bien es cierto que se han documentado otros ejemplos en la segunda mitad del s. I d. C. -Tumba de Servilia en Carmona, Termas y Estancia 1 de la Casa del Larario de Bilbilis-, la mayor parte se datan en el s. II d. C. Aunque es evidente su popularidad en la citada centuria, también existen testimonios posteriores como demuestran las pinturas del s. vi del baptisterio de Barcino; su utilización se prolonga hasta la Edad Media, como podemos 
L. Íniguez Berrozpe y C. Guiral Pelegrín / El sistema de relación continua

en la pintura mural romana de Hispania

\begin{tabular}{|c|c|c|c|c|c|c|}
\hline LOCALIDAD & Estructura & ZONA & $\begin{array}{l}\text { Elementos } \\
\text { DECORATIVOS }\end{array}$ & Fondo & Cronología & BibLIOGRAFÍA \\
\hline $\begin{array}{l}\text { Almedinilla } \\
\text { (Córdoba) }\end{array}$ & Villa (Estancia LXII) & zona superior & & blanco & $\begin{array}{c}\text { fin s. III- } \\
\text { inicios s. IV } \\
\end{array}$ & Cánovas, 2002 \\
\hline $\begin{array}{l}\text { Andelos (Mendigorría, } \\
\text { Navarra) }\end{array}$ & Casa de las Pinturas & $\begin{array}{l}\text { zona superior } \\
\text { y/o techo }\end{array}$ & & blanco & s. II d. C. & Mezquíriz, 2009 \\
\hline Carmona (Sevilla) & $\begin{array}{l}\text { Necrópolis (Tumba de } \\
\text { Servilia) }\end{array}$ & techo & & blanco & $\begin{array}{l}\text { mediados } \\
\text { s. I d. C. }\end{array}$ & $\begin{array}{l}\text { Abad, 1982: } \\
\text { 189-190; Guiral, } \\
\text { 2002: 96-97 } \\
\end{array}$ \\
\hline $\begin{array}{l}\text { Carthago Nova } \\
\text { (Cartagena) }\end{array}$ & $\begin{array}{l}\text { Edificio del Atrio (Estancias } \\
\text { sobre Habitación 11) }\end{array}$ & $\begin{array}{l}\text { zona superior } \\
\text { y techo }\end{array}$ & $\begin{array}{l}\text { cabezas } \\
\text { femeninas y } \\
\text { aves }\end{array}$ & amarillo & s. II d. C. & $\begin{array}{l}\text { Fernández et al., } \\
\text { 2014: 479-481 }\end{array}$ \\
\hline $\begin{array}{l}\text { Carthago Nova } \\
\text { (Cartagena) }\end{array}$ & $\begin{array}{l}\text { Edificio del Atrio (Estancias } \\
\text { sobre Habitación 11) }\end{array}$ & $\begin{array}{l}\text { zona superior } \\
\text { y techo }\end{array}$ & & verde & s. II d. C. & $\begin{array}{l}\text { Fernández et al., } \\
\text { 2014: 479-481 }\end{array}$ \\
\hline $\begin{array}{l}\text { Carthago Nova } \\
\text { (Cartagena) }\end{array}$ & $\begin{array}{l}\text { Edificio del Atrio (Estancia } \\
\text { sobre la Habitación 15) }\end{array}$ & zona superior & $\begin{array}{l}\text { cabezas } \\
\text { femeninas }\end{array}$ & blanco & s. II d. C. & $\begin{array}{l}\text { Fernández et al., } \\
\text { 2014: 479-481 }\end{array}$ \\
\hline $\begin{array}{l}\text { Carthago Nova } \\
\text { (Cartagena) }\end{array}$ & $\begin{array}{l}\text { Cerro de El Molinete } \\
\text { (Sondeo 39) }\end{array}$ & \begin{tabular}{|l|} 
zona superior \\
de la pared y/o \\
techo
\end{tabular} & $\begin{array}{l}\text { cabeza } \\
\text { femenina }\end{array}$ & blanco & s. II d. C. & $\begin{array}{l}\text { Fernández et al., } \\
\text { 2014: } 479\end{array}$ \\
\hline $\begin{array}{l}\text { Carthago Nova } \\
\text { (Cartagena) }\end{array}$ & Domus de la Fortuna & $\begin{array}{l}\text { zona superior } \\
\text { y techo }\end{array}$ & $\begin{array}{l}\text { plumas de } \\
\text { pavo }\end{array}$ & blanco & $\begin{array}{l}\text { primera } \\
\text { mitad } \\
\text { s. II d. C. }\end{array}$ & $\begin{array}{l}\text { Fernández, 2008: } \\
\text { 268-270 }\end{array}$ \\
\hline $\begin{array}{l}\text { Carthago Nova } \\
\text { (Cartagena) }\end{array}$ & $\begin{array}{l}\text { Teatro } \\
\text { (porticus post scaenam) }\end{array}$ & zona superior & $\begin{array}{l}\text { figuras } \\
\text { zoomorfas }\end{array}$ & blanco & s. II d. C. & $\begin{array}{l}\text { Fernández y } \\
\text { Castillo, 2020: } \\
108-112 \\
\end{array}$ \\
\hline $\begin{array}{l}\text { Carthago Nova } \\
\text { (Cartagena) }\end{array}$ & $\begin{array}{l}\text { Casa de la c/ Duque, } 37 \\
\text { (pasillo del peristilo) }\end{array}$ & & & blanco & \begin{tabular}{|c|} 
fin s. I- \\
principio s. II \\
d. C. \\
\end{tabular} & \begin{tabular}{|l|} 
Suárez y \\
Fernández, 2007: \\
$81-82,103$ y 106 \\
\end{tabular} \\
\hline $\begin{array}{l}\text { Cauca } \\
\text { (Coca, Segovia) }\end{array}$ & $\begin{array}{l}\text { Edificio de los Cinco } \\
\text { Caños (Estancia 1) }\end{array}$ & techo & $\begin{array}{l}\text { plumas de } \\
\text { pavo }\end{array}$ & blanco & s. II d. C. & $\begin{array}{l}\text { Martín et al., } \\
\text { 2020: 201-202 }\end{array}$ \\
\hline Centcelles (Tarragona) & $\begin{array}{l}\text { Villa-Mausoleo (cámara } \\
\text { debajo de la cúpula) }\end{array}$ & $\begin{array}{l}\text { cubierta } \\
\text { abovedada }\end{array}$ & & azul oscuro & $\begin{array}{l}\text { 325-350 } \\
\text { d. C. }\end{array}$ & Abad, 1982: 250 \\
\hline $\begin{array}{l}\text { Colonia Iulia Augusta } \\
\text { Emerita (Mérida) }\end{array}$ & Edificio metróaco & zona superior & & blanco & s. IV d. C. & \begin{tabular}{|l|} 
Heras, 2011: \\
$31-32$
\end{tabular} \\
\hline $\begin{array}{l}\text { Colonia Iulia Augusta } \\
\text { Faventia Paterna } \\
\text { Barcino (Barcelona) } \\
\end{array}$ & Baptisterio de la basílica & techo & & blanco & s. vi d. C. & Albiol, 2013 \\
\hline $\begin{array}{l}\text { Colonia Clunia } \\
\text { Sulpicia (Peñalba de } \\
\text { Castro, Burgos) } \\
\end{array}$ & $\begin{array}{l}\text { Casa Taracena } \\
\text { (Habitación 58) }\end{array}$ & & & blanco & $\begin{array}{l}\text { fin del } \\
\text { s. II d. C. }\end{array}$ & $\begin{array}{l}\text { Abad, 1982: } \\
97-98\end{array}$ \\
\hline $\begin{array}{l}\text { Colonia Iulia Ilici } \\
\text { Augusta (Elche) }\end{array}$ & & techo & & amarillo & s. II d. C. & \begin{tabular}{|l|} 
Cebrián y \\
Fernández Díaz, \\
2004: 143 \\
\end{tabular} \\
\hline $\begin{array}{l}\text { Colonia Iulia Ilici } \\
\text { Augusta (Elche) }\end{array}$ & Casa del Sector 5e & techo & $\begin{array}{l}\text { ¿cabezas } \\
\text { femeninas? }\end{array}$ & rojo & s. II d. C. & Abad, 1982: 32 \\
\hline $\begin{array}{l}\text { Colonia Patricia - } \\
\text { Corduba (Córdoba) }\end{array}$ & $\begin{array}{l}\text { Domus del Sátiro } \\
\text { (Cubiculum 5) }\end{array}$ & techo & & $\begin{array}{l}\text { casetones } \\
\text { de color } \\
\text { verde y } \\
\text { rojo }\end{array}$ & s. II d. C. & $\begin{array}{l}\text { Castro y Cánovas, } \\
\text { 2010: 135; } \\
\text { Cánovas, 2010: } \\
\text { 434-435 } \\
\end{array}$ \\
\hline $\begin{array}{l}\text { Colonia Victrix Iulia } \\
\text { Lepida Celsa (Velilla } \\
\text { de Ebro, Zaragoza) }\end{array}$ & $\begin{array}{l}\text { Domus de los Delfines } \\
\text { (Estancia 12. Oecus } \\
\text { triclinar) } \\
\end{array}$ & $\begin{array}{l}\text { techo (tramo } \\
\text { abovedado) }\end{array}$ & & negro & $25-35$ d. C. & $\begin{array}{l}\text { Mostalac y } \\
\text { Beltrán, } 1994\end{array}$ \\
\hline $\begin{array}{l}\text { Complutum (Alcalá } \\
\text { de Henares) }\end{array}$ & $\begin{array}{l}\text { Casa de los Grifos } \\
\text { (Estancia F) }\end{array}$ & zona superior & & negro & $\begin{array}{c}\text { segunda } \\
\text { mitad } \\
\text { del s. I d. C. }\end{array}$ & $\begin{array}{l}\text { Sánchez Montes, } \\
\text { 2014: 64-65 }\end{array}$ \\
\hline Comunión (Álava) & $\begin{array}{l}\text { Villa de Cabriana (fondo } \\
\text { de la cisterna del peristilo } \\
\text { y estanque contiguo) }\end{array}$ & $\begin{array}{l}\text { zona media } \\
\text { y/o superior }\end{array}$ & & blanco & $\begin{array}{l}\text { inicios del } \\
\text { s. II d. C. }\end{array}$ & $\begin{array}{l}\text { Filloy et al., 1992: } \\
\text { 109-111 }\end{array}$ \\
\hline
\end{tabular}




\begin{tabular}{|c|c|c|c|c|c|c|}
\hline LOCALIDAD & ESTRUCTURA & Zona & $\begin{array}{c}\text { ELEMENTOS } \\
\text { DECORATIVOS }\end{array}$ & FONDO & Cronología & BiBLIOGRAFÍA \\
\hline Comunión (Álava) & $\begin{array}{l}\text { Villa de Cabriana (fondo } \\
\text { de la cisterna del peristilo y } \\
\text { en estanque contiguo) }\end{array}$ & $\begin{array}{l}\text { zona superior } \\
\text { y/o techo }\end{array}$ & & blanco & $\begin{array}{l}\text { inicios del } \\
\text { s. II d. C. }\end{array}$ & $\begin{array}{l}\text { Filloy et al., 1992: } \\
\text { 111-112 }\end{array}$ \\
\hline Comunión (Álava) & $\begin{array}{l}\text { Villa de Cabriana (fondo } \\
\text { de la cisterna del peristilo y } \\
\text { en estanque contiguo) }\end{array}$ & $\begin{array}{l}\text { zona media } \\
\text { y/o superior? }\end{array}$ & & blanco & $\begin{array}{l}\text { inicios del } \\
\text { s. II d. C. }\end{array}$ & $\begin{array}{l}\text { Filloy et al., 1992: } \\
\text { 109-111 }\end{array}$ \\
\hline $\begin{array}{l}\text { El Pueyo de Belchite } \\
\text { (Zaragoza) }\end{array}$ & Domus (Espacio 5) & zona superior & & amarillo & s. II d. C. & $\begin{array}{l}\text { Íñiguez y } \\
\text { Rodríguez, } 2020 \\
\end{array}$ \\
\hline $\begin{array}{l}\text { Graccurris (Alfaro, } \\
\text { La Rioja) }\end{array}$ & Casa 4 (н. 2) & zona superior & $\begin{array}{l}\text { cabezas } \\
\text { femeninas }\end{array}$ & blanco & s. II d. C. & $\begin{array}{l}\text { Ińiguez et al., } \\
2021\end{array}$ \\
\hline Herrera (Sevilla) & $\begin{array}{l}\text { Caldarium del conjunto } \\
\text { termal }\end{array}$ & bóveda & $\begin{array}{l}\text { imitación opus } \\
\text { musivum }\end{array}$ & blanco & fin s. II d. C. & $\begin{array}{l}\text { Fernández Díaz, } \\
\text { 2016: 526-527 }\end{array}$ \\
\hline Herrera (Sevilla) & $\begin{array}{l}\text { Vestíbulo de acceso al } \\
\text { frigidarium }\end{array}$ & & & blanco & fin s. II d. C. & $\begin{array}{l}\text { Fernández Díaz, } \\
\text { 2016: 526-527 } \\
\end{array}$ \\
\hline Italica (Sevilla) & & & & blanco & $\begin{array}{l}\text { mediados } \\
\text { s. II d. C. }\end{array}$ & $\begin{array}{l}\text { Abad, 1982: } \\
218-219\end{array}$ \\
\hline Italica (Sevilla) & Casa de la Exedra & bóveda & & blanco & s. II d. C. & Abad, 1982: 229 \\
\hline Lucus Augusti (Lugo) & Rua Nova & & & blanco & & $\begin{array}{l}\text { González, 2005: } \\
\text { 79-80 }\end{array}$ \\
\hline Lucentum (Alicante) & $\begin{array}{l}\text { Domus de la Puerta } \\
\text { Oriental (Estancia Norte) }\end{array}$ & $\begin{array}{l}\text { zona superior } \\
\text { y/o techo }\end{array}$ & $\begin{array}{l}\text { cabeza } \\
\text { femenina } \\
\text { y aves } \\
\end{array}$ & blanco & s. II d. C. & $\begin{array}{l}\text { Fernández Díaz, } \\
\text { 2000-2001: } \\
35-59 \\
\end{array}$ \\
\hline $\begin{array}{l}\text { Municipium Augusta } \\
\text { Bilbilis (Calatayud, } \\
\text { Zaragoza) }\end{array}$ & $\begin{array}{l}\text { Hallado en las termas } \\
\text { (posiblemente } \\
\text { perteneciente a la Insula I) }\end{array}$ & $\begin{array}{l}\text { zona superior } \\
\text { y techo }\end{array}$ & & rojo & $\begin{array}{l}\text { segunda } \\
\text { mitad } \\
\text { s. I d. C. }\end{array}$ & $\begin{array}{l}\text { Guiral y Martín- } \\
\text { Bueno, 1996: } \\
111-134 \\
\end{array}$ \\
\hline $\begin{array}{l}\text { Municipium Augusta } \\
\text { Bilbilis (Calatayud, } \\
\text { Zaragoza) }\end{array}$ & $\begin{array}{l}\text { Casa del Ninfeo/Larario } \\
\text { (Estancia 1) }\end{array}$ & $\begin{array}{l}\text { zona superior } \\
\text { y techo }\end{array}$ & & rojo & $\begin{array}{l}\text { segunda } \\
\text { mitad del s. I } \\
\text { d. C. } \\
\end{array}$ & $\begin{array}{l}\text { Guiral y Martín- } \\
\text { Bueno, 1996: } \\
\text { 352-355 }\end{array}$ \\
\hline $\begin{array}{l}\text { Municipium Urbs } \\
\text { Victrix Osca (Huesca) }\end{array}$ & c/ Dormer & zona media & & negro & $\begin{array}{c}\text { finales del s. I } \\
\text { d. C. }\end{array}$ & $\begin{array}{l}\text { Guiral et al., } \\
\text { 2018: 222-231 }\end{array}$ \\
\hline $\begin{array}{l}\text { Santa Eulalia de } \\
\text { Bóveda (Lugo) }\end{array}$ & $\begin{array}{l}\text { Santuario tardo-romano } \\
\text { (cripta) }\end{array}$ & bóveda & $\begin{array}{l}\text { aves en la zona } \\
\text { lateral }\end{array}$ & blanco & ss. IV-IX d. C. & $\begin{array}{l}\text { Abad, 1982: } \\
151-152\end{array}$ \\
\hline $\begin{array}{l}\text { Segobriga (Saelices, } \\
\text { Cuenca) }\end{array}$ & $\begin{array}{l}\text { Domus de G. Iulius Silvanus } \\
\text { (Habitación 2) }\end{array}$ & techo & & blanco & fin s. II d. C. & \begin{tabular}{|l|} 
Cebrián y \\
Fernández, 2004: \\
$137-146$ \\
\end{tabular} \\
\hline $\begin{array}{l}\text { Sisapo (La Bienvenida, } \\
\text { Ciudad Real) }\end{array}$ & $\begin{array}{l}\text { Domus de las Columnas } \\
\text { Rojas (viridarium) }\end{array}$ & techo & & blanco & s. II d. C. & Hevia et al., 2007 \\
\hline Valentia (Valencia) & $\begin{array}{l}\text { Domus de Terpsícore } \\
\text { (derrumbe de estancias } \\
\text { anteriores de la domus) } \\
\end{array}$ & techo & & blanco & s. II d. C. & $\begin{array}{l}\text { López et al., } \\
\text { 1994: } 157\end{array}$ \\
\hline Valentia (Valencia) & Plaza de Cisneros (relleno) & techo & $\begin{array}{l}\text { Plumas de } \\
\text { pavo }\end{array}$ & blanco & s. II d. C. & Jiménez, 2000: 32 \\
\hline Valentia (Valencia) & $\begin{array}{l}\text { Domus de Terpsícore (Sala } \\
\text { del mosaico de Terpsícore) }\end{array}$ & techo & $\begin{array}{l}\text { plumas de } \\
\text { pavo }\end{array}$ & blanco & s. II d. C. & $\begin{array}{l}\text { López et al., } \\
\text { 1994: } 168 \text { y } 172\end{array}$ \\
\hline $\begin{array}{l}\text { Veleia (Iruña de Oca, } \\
\text { Vitoria) }\end{array}$ & $\begin{array}{l}\text { Vivienda del Sector J } \\
\text { (Recinto 1) }\end{array}$ & & & blanco & s. II d. C. & $\begin{array}{l}\text { Filloy et al., 1992: } \\
108\end{array}$ \\
\hline Vildé (Soria) & Tumba & bóveda & & verde & s. II d. C. & Abad, 1982: 247 \\
\hline Yecla (Murcia) & Villa de los Torrejones & zona superior & & amarillo & s. II d. C. & $\begin{array}{l}\text { Fernández Díaz, } \\
\text { 2004a: 343-346 }\end{array}$ \\
\hline
\end{tabular}

FIG. 14. Sistemas de relación continua en la pintura romana de Hispania. 
comprobar en la iglesia asturiana de San Julián de los Prados, Oviedo, del s. Ix, decorada con estos esquemas tanto en las bóvedas como en los muros de las naves (Arias, 1999: 93-101).

La mayor parte de los ejemplos del s. II se disponen sobre un fondo blanco y, ante esta evidencia, cabe preguntarse si el color de fondo es un marcador cronológico, más aún si tenemos en cuenta que no constatamos ningún sistema de relación continua con este fondo en el s. I d. C. Sin embargo, tampoco podemos afirmar que sea exclusivo de la segunda centuria, tal y como avala el techo de la Habitación LXII de la villa romana de El Ruedo fechada entre los ss. III y Iv. Respecto a la utilización de otros colores para elaborar los fondos de estas decoraciones, la escasa muestra conservada de conjuntos representativos de cada pigmento no nos permite establecer ninguna conclusión al respecto.

Como ya hemos apuntado, los diseños seleccionados para el sistema objeto de estudio son muy variados, pero observamos algunos datos interesantes. Las composiciones basadas en patrones geométricos, y dentro de ellos aquellos que emulan más directamente el cruce de vigas que se situaría en el techo de una estancia, nacen en el s. I d. C., siendo el techo del Oecus triclinar de Celsa el sistema de relación continua pintado más antiguo de Hispania. Ahora bien, la decoración procedente de la Estancia 5 de la domus de El Pueyo de Belchite y también la de la Casa de los Grifos de Complutum confirman que este modelo perdura en el s. II d. C. Por otra parte, el resto de decoraciones analizadas permiten corroborar que los sistemas en red con tramas total o parcialmente vegetalizadas no están presentes en territorio hispano hasta principios del s. II d. C.

Si pasamos ahora a hablar de los motivos que ornan estos esquemas, tres son los que destacan, más allá de los florales que aparecen, con variadas formas, en casi todas las pinturas documentadas. El primer elemento que destacamos son las denominadas 'cabezas femeninas' o 'cabezas mofletudas', término con el que actualmente designamos a las tradicionalmente denominadas 'máscaras lunares de tipo fantástico', ya que ni se trata de un objeto utilizado para tapar total o parcialmente el rostro ni su color

Ediciones Universidad de Salamanca / 요 es un 'gris lunar' pues es evidente que trata de imitar un modelo metálico en muchos casos, hipótesis corroborada por el hecho de que hay varios ejemplos donde el tono no es plateado sino dorado (Barbet, 2008: 359). En nuestro estudio hemos evidenciado cabezas femeninas -normalmente alternando con otros motivos- en el Edificio del Atrio del Cerro del Molinete, en la Domus de la Puerta Oriental de $L u$ centum, en la casa del Sector 5e de Ilici y en la Casa 4 de Graccurris. De forma general, estas cabezas se caracterizan por su forma redondeada, están vistas de frente, con ojos abiertos y expresión imperturbable -no en todos los casos-, y por carecer de cuello y cabellos visibles, pues estos se hallan recogidos en un tocado que se complementa con unos pendientes consistentes en dos esferas que, a veces, finalizan en un apéndice que cuelga o se enrosca sobre sí mismo, creando unas volutas más o menos complejas. Su gama cromática presenta, mayoritariamente, dos variantes: la primera oscila entre los colores grises, verdes y azulados y la segunda se decanta por tonos dorados, ambas con pinceladas blancas, que crean juegos de luces y sombras y que remiten a modelos metálicos.

Existe una falta de estudio global sobre este tipo de cabezas que trate la variedad tipológica de sus tocados, su disposición en la pared $\mathrm{u}$ otros aspectos más simbólicos ya que también pueden aparecer como oscilla. Por tanto, nada podemos concluir, tan solo que se trata de un elemento ornamental, en el que parece haber una intencionalidad de imitar tonos metálicos, que tiene cierto éxito a partir del III estilo, prolongándose su utilización hasta el s. II, y al que a veces se le añaden atributos de un dios concreto y, en muchos casos, egiptizantes. Se disponen de forma individual o acompañando a otros ornamentos, por ejemplo, candelabros, y en cualquier zona de la pared o techo (Benetti, 2020: 218-219 y 225227). Es a partir del IV estilo cuando se introducen en los sistemas de relación continua, siendo populares en la pintura hispana del s. II d. C.22. Un dato curioso, digno de señalar, es la elevada presencia de

22 Íńiguez, L. y Madurga, L.: "Las cabezas femeninas mofletudas en pintura mural romana. Aproximación a una nueva interpretación”, Pyrenae, en prensa.

Zephyrus, LXXXVIII, julio-diciembre 2021, 163-189 
estas cabezas en este tipo compositivo en Hispania, en comparación con las pinturas de la zona campana, donde solo podemos citar las pinturas de la Casa de Pinarius Cerealis -III 4, 4; PPM III: 477, fig. 48-. En las pinturas de otras provincias tampoco son habituales, así solamente conocemos las que decoraban el techo del Corredor 2 de la Insula 21, 2 de Verulamium (Davey y Ling, 1982: pl. CXII), de finales del s. II; la bóveda de la habitación adyacente al Local 2 de la villa de Vallon (Suiza), entre finales del s. II e inicios del III (Fuchs, 1995: 122-126, figs. 5 y 6), y, finalmente, la decoración vI-5 de las Termas de Saint-Roman-en-Gal, de finales del s. II (Blanc y Lebot-Helly, 1997: 263-265, fig. 4).

Un segundo motivo que, en ocasiones, aparece alternando con el anterior, son las aves, documentadas en uno de los conjuntos procedente de la estancia superior de la Habitación 11 del Edificio del Atrio de Carthago Nova, en la Domus de la Puerta Oriental de Lucentum, en la Villa de los Torrejones y en Santa Eulalia de Bóveda.

Finalmente, también podemos apuntar la relativa popularidad de las plumas de pavo en las composiciones hispanas, como demuestran las pinturas de la Domus de la Fortuna de Carthago Nova, de la denominada Domus de Terpsícore de Valentia, las halladas en la plaza de Cisneros de la misma ciudad y las exhumadas en el Edificio de los Cinco Caños en Cauca, Segovia. Como ocurre con las cabezas femeninas y las aves, también las plumas de pavo son habituales en pintura romana por su evidente efecto decorativo y así las vemos en la villa de Oplontis, en el interior de un jarrón; en la Casa de L. Caecilius Iucundus -v 1, 26- de Pompeya, concretamente en una cenefa del panel medio, o en el techo de la Casa del Salone Nero de Herculano -v 13-. Es cierto que es más rara su utilización en sistemas de relación continua, de modo que solo podemos citar las pinturas de Bössingen (Fuchs, 1989: 69-70, fig. 20a), de la segunda mitad del s. II y principios del s. III; las procedentes de la Villa de Colombier (Bujard y Provenzale, 2004), y los dos conjuntos, muy similares, hallados en el Collège Saint-Stanislas y en la rue des Carmes de Poitiers, de datación incierta, aunque la destrucción de los enclaves acontece en el s. II d. C. Allag y Vibert-Guigue (2001-2002: 154) se cuestionan, al ser el pavo real un ave propia de Juno, si la representación de sus plumas estaría ligada a esta divinidad aportando, en la estancia donde se dispusieran, una suerte de función protectora. En cualquier caso, los autores reconocen su utilización con fines puramente ornamentales.

En último lugar, conviene abordar la posibilidad de identificar talleres de artesanos en Hispania, a través de los sistemas de relación continua. Por supuesto, no basta solo con analizar estas decoraciones para dar por hecho el trabajo de los pictores romanos en varios sectores de una misma casa, ciudad o territorio, pero sin duda el diseño y la factura técnica, los colores y los ornamentos escogidos han sido tenidos en cuenta por los investigadores, entre otros muchos aspectos, para aportar las conjeturas que pasamos a enumerar.

Un taller fue identificado trabajando en varias domus de Bilbilis. La similitud, entre otros aspectos, entre las relaciones continuas de los conjuntos hallados en las termas y en la Casa del Larario -Estancia $1-$, respectivamente, dieron pie a la hipótesis sobre un grupo de artesanos que trabajaron en la ciudad a comienzos de la segunda mitad del s. I d. C. (Guiral y Martín-Bueno, 1996: 473-474). También podemos mencionar el posible taller que ejerció en $\mathrm{Va}$ lentia, a juzgar por la similitud de las decoraciones de la conocida como Domus de Terpsícore y de la plaza de Cisneros (Jiménez, 2000: 32).

En cuanto a los talleres que trabajan en distintos establecimientos repitiendo esquemas, aunque con evidentes variaciones, destacamos dos grupos: el primero corresponde a la zona de Carthago Nova y su ager. Fernández Díaz (2009: 68; 2014: 481; 2016b: 139) ha documentado el que ha denominado 'taller de las máscaras', refiriéndose a lo que en este trabajo hemos llamado 'cabezas femeninas', pintando en el Edificio del Atrio del Molinete y en otro sector del mismo cerro, a juzgar por el conjunto hallado en el Sondeo 39. Su trabajo, que se desarrolló en el s. II d. C., se extendería hasta la Villa de los Torrejones, en la actual Yecla ${ }^{23}$.

23 En este conjunto no hay máscaras, pero el diseño, los motivos y los colores utilizados en otra de las habitaciones, la superior a la Estancia 11, incitan a pensar que el 'taller de las máscaras' se desplazó hasta este enclave. 
en la pintura mural romana de Hispania

El segundo grupo corresponde a un taller que, también en el s. II d. C., debió pintar las estancias de Graccurris, Veleia y la Villa de Cabriana. No parece que haya ninguna duda, al menos en el caso de los dos primeros, es decir, que el taller que pintó la Habitación 2 de la Casa 4 de Graccurris lo hizo también en Veleia. En este último yacimiento, no solo la relación continua hallada en la vivienda del Sector J avala esta hipótesis, sino también el conjunto de la denominada 'Habitación de las Pinturas', que presenta zócalo y zona media iguales a los de Graccurris (Íñiguez et al., 2021: 284). No consideramos que los fragmentos hallados en la vivienda del Sector J decoraban la zona superior o techo del conjunto de la 'Habitación de las Pinturas', pero tendemos a suponer que los artesanos que trabajaron el Graccurris pudieron hacerlo en estructuras o estancias de Veleia.

Podemos concluir, así, que la repetición de ciertos motivos, como las cabezas femeninas, en las composiciones de relación continua hispanas, si las comparamos con el resto de provincias, no debe sorprendernos pues, sin duda, son producto de la circulación de talleres en nuestra geografía.

El resultado final de este estudio es la constatación de la existencia en la pintura hispana de un esquema compositivo, presente en Italia y en las provincias del Imperio, que tiene sus orígenes en las imitaciones de los techos casetonados, pero que experimenta una intensa evolución hasta las composiciones vegetalizadas, en las que se integran distintos motivos figurados, y que, siendo muy popular en el s. II d. C. y característico de la decoración de las cubiertas, desciende a la zona superior e incluso ocupa la zona media de la pared.

\section{Bibliografía}

ABAD, A. (1982): La pintura romana en España. Madrid: Univ. de Alicante-Univ. de Sevilla.

Abadie-Reynal, C. y Darmon, J. P. (2003): "La maison et la mosaïque des Synaristôsai (Les Femmes au déjeuner de Ménandre)", Journal of Roman Archaeology, Supp. 51, pp. 79-100.

Ediciones Universidad de Salamanca / 용
Albiol, E. (2013): "Una pintura de sostre de l'antiguitat tardana al baptisteri de Barcelona", Quaderns d'Arqueologia i Historia de la ciutat de Barcelona, 9, pp. 165-183.

Allag, C. y Vibert-Guigue, C. (2001-2002): "Peintures antiques à Poitiers. Décors à réseau et plumes de paon”, Aquitania, XvıII, pp. 137-155.

Arias, L. (1999): La pintura mural en el Reino de Asturias en los ss. $I X Y X$. Oviedo.

BARBET, A. (1983): "Quelques rapports entre mosaïques et peintures murales à l'époque romaine”. En Mosaïque. Recueil d'hommages à Henri Stern. Paris: Éditions Recherche sur les Civilisations, pp. 43-53.

BARBET, A. (1985): La peinture murale romaine. Les styles décoratifs pompéiens. Paris: Picard.

Barbet, A. (2003): "Les décors centrés en mosaïque et leur écho en peinture murale", Revue Archéologique, 2, pp. 319-330.

BARBET, A. (2008): La peinture murale en Gaule romaine. Paris: Picard.

Barbet A.; Douaud, R. y Laniepce V. (1997): Imitations d'opus sectile et décors à réseau, essai de terminologie. Bulletin de liaison du Centre du CEPMr, 12. Paris.

Benetti, I. (2020): "Gorgoneia o teste di luna: un aproccio terminologico al motivo ornamentale". En Donati, F. y Benetti, I. (eds.): Sistemi decorativi della pittura antica: funzione e contesto. Atti del II coloquio AIRPA (Pisa, 2018). Roma: Quasar, pp. 217-228.

Bertacchi, L. (1963): Nuovi mosaici figurati di Aquileia. Aquileia: Associazione Nazionale per Aquileia.

Blanc, N. y Le Bot-Helly, A. (1997): "Les décors peints des petits thermes nord à Saint-Romain-enGal (Rhône)", Gallia, 54, pp. 261-275.

Blanco-Rotea, R.; Benavides, R.; Sanjurjo, J. y FerNÁNDEZ DíAz, D. (2009): "Evolución constructiva de Santa Eulalia de Bóveda (Lugo, Galicia)", Arqueología de la Arquitectura, 6, pp. 149-198.

Bujard, S. y Provenzale, V. (2004): "Le plafond aux plumes de paon de la Villa de Colombier (Suisse)". En Borhy, L. (dir.): Plafonds et voûtes à l'époque antique. Actes du vIIIe Colloque international de l'AIPMA (Budapest, 2001). Budapest: Pytheas Publishing, pp. 319-320.

Cánovas, A. (2002): La decoración pictórica de la villa de El Ruedo (Almedinilla, Córdoba). Las pinturas de la Estancia LXII. Córdoba: Univ. de Córdoba.

Cánovas, A. (2010): "La arquitectura doméstica de la zona occidental de la Colonia Patricia Corduba". En Vaquerizo, D. y Murillo, J. F. (eds.): El anfiteatro

Zephyrus, LXXXVIII, julio-diciembre 2021, 163-189 
romano de Córdoba y su entorno urbano. Análisis Arqueológico (ss. I-XIII d. C.). Monografías de Arqueología Cordobesa, 19. Córdoba, vol. 2, pp. 415-438.

Castro, E. y Cánovas, U. (2009-2010): "La domus del parque infantil de Tráfico (Córdoba)", Anejos de Arqueología Cordobesa, 2, pp. 121-140.

Cavari, F. (1985): "Il Cubiculo 34". En Carandini, A. (ed.): Settefinestre. Una villa schiavistica nell'Etruria romana, II. Modena: Panini, pp. 231-234.

Cebrián, R. y Fernández Díaz, A. (2004): "Un techo pintado en la domus de G. Iulius Silvanus en Segobriga (Saelices, Cuenca, Conventus Carthaginensis)". En Borhy, L. (dir.): Plafonds et voûtes à l'époque antique. Actes du viIIe Colloque international de l'AIPMA (Budapest, 2001). Budapest: Pytheas Publishing, pp. 137-146.

Cerulli, G.; Aoyagi, M.; De Caro, S. y Pappalardo, U. (dirs.) (1993): La peinture de Pompéi. Temoignages de l'art romain dans la zone ensevelie par Vésuve en 79 ap. J.-C. Paris: Hazan.

Colpo, I. (2004): "Analogie e differenze tra schemi di soffito e di pavimento". En Borhy, L. (dir.): Plafonds et voûtes à l'époque antique. Actes du ville Colloque international de l'AIPMA (Budapest, 2001). Budapest: Pytheas Publishing, pp. 337-340.

Dardenay, A. (2014): "La peinture en Narbonnaise". En Capus, P. y Dardenay, A. (coords.): L'empire de la couleur de Pompéi an sud des Gaules (catalogue de l'exposition) (Toulouse, 2014-2015). Toulouse: Musée Saint Raymond, pp. 72-79.

Darmon, J. P. (2001): “L'Italie, source et reflet". En Recherches franco-tunisiennes sur la mosaïque de l'Afrique antique. 2. Trames géométriques végétalisées. Rome: École Française de Rome, pp. 111-120.

De Vos, M. (1982): "Pavimenti e pitture. Terzo e quarto stile negli scarichi trovati sotto i pavimenti", $R \ddot{o}-$ mische Mitteilungen, 89 (2), pp. 315-352.

Didonè, A.; Helg, R.; Malgieri, A. y Salvo, G. (2014): "Glossario per la schedatura delle decorazioni pittoriche”. En Salvadori, M. y Scagliarini, D. (eds.): TECT. Un progetto per la conoscenza della pittura parietale romana nell'Italia settentrionale. Padova: Univ. degli Studi di Padova, pp. 21-43.

Dubois, Y. (2016): Ornementation et discours architectural de la villa romaine d'Orbe Boscéaz. Cahiers Archéologie Romande. Lausanne.

Dunbabin, K. (1999): Mosaics of the Greek and Roman world. Cambridge: Cambridge University Press.

Eristov, H. y Robin, S. (2011): "Les décors peints de la fouille du collège Sainte-Barbe (Paris 5e)". En
Balmelle, C.; Eristov, H. y Monier, F. (eds.): Décor et architecture en Gaule entre l'Antiquité et le Moyen Âge. Actes du colloque international (Toulouse, 2008). Bordeaux: Aquitania, pp. 151-159.

Escrivá, M. I.; JimÉnez, J. L.; Machancoses, M. y Rivera, A. (2016): "Domus de Terpsícore, Valentia (Valencia)”. En Rodríguez, O.; Tran, N. y Soler, B. (coords.): Los espacios de reunión de las asociaciones romanas. Diálogos desde la arqueología y la historia, en homenaje a Bertrand Goffaux. Sevilla: Univ. de Sevilla, pp. 428-434.

Esposito, D. (2019): "Il iv stile nella Villa A de Oplontis". En Clarke, J. R. y Muntasser, N. Oplontis: Villa A ('of Poppaea') at Torre Annunziata, Italy. Volume 2. The Decorations: Painting, Stucco, Pavements, Sculptures. American Council of Learned Societies Humanities: E-Book Series.

Falzone, S. (2007): Ornata aedificia. Pitture parietali delle case ostiense. Roma: Librería dello Stato.

Fernández Díaz, A. (1999): "La pintura mural de la villa romana de Los Torrejones (Yecla, Murcia)", Anales de Prehistoria y Arqueología, 15, pp. 57-86.

Fernández DíAz, A. (2000-2001): "Algunos restos pictóricos de la ciudad de Lucentum (Tossal de Manises-Alicante)", Lucentum, XIX-xx, pp. 1-82.

Fernández Díaz, A. (2004a): "El sistema en red en el Conventus Carthaginensis (Hispania)". En BorHy, L. (dir.): Plafonds et voûtes à l'époque antique. Actes $d u$ vIIIe Colloque international de l'AIPMA (Budapest, 2001). Budapest: Pytheas Publishing, pp. 343-348.

Fernández Díaz, A. (2004b): "Los programas ornamentales. Pintura y mosaico". En Abad, L. y HerNÁNDEZ, M. (dirs.): Iberia, Hispania, Spania. Una mirada desde Ilici. Alicante: CAM, pp. 167-174.

Fernández Díaz, A. (2008): La pintura romana de Carthago Nova. Evolución del programa pictórico a través de los estilos, talleres y otras técnicas decorativas. Monografías del Museo Arqueológico de Murcia. Murcia.

Fernández Díaz, A. (2009): "Yecla en el contexto de época romana”. En MuÑoz, F. J. (ed.): Yecla. Memorias de su identidad. Murcia: Editum, pp. 63-71.

Fernández DíAz, A. (2016a): "La decoración pictórica”. En Hidalgo, R. (coord.): Las villas romanas de la Bética. Sevilla: Univ. de Sevilla, pp. 491-550.

Fernández Díaz, A. (2016b): "Pintura mural romana en el Barrio del Foro". En Noguera, J. M.; Madrid, M. a J. y MarTínez, I. (eds.): Barrio del Foro Romano (Molinete, Cartagena). Proyecto Integral de Recuperación y Conservación. Cartagena: Ayto. de Cartagena, pp. 131-139.

Zephyrus, LXXXVIII, julio-diciembre 2021, 163-189 
en la pintura mural romana de Hispania

Fernández Díaz, A. y Castillo, G. (2020): "La decoración pictórica de la porticus post scaenam del teatro romano de Cartagena". En Fernández, A. y CastiLLO, G. (eds.): La pintura romana en Hispania: del estudio de campo a su puesta en valor. Murcia: Univ. de Murcia, pp. 96-120.

Fernández Díaz, A.; Noguera, J. M. y Suárez, L. (2014): "Novedades sobre la gran arquitectura de Carthago Nova y sus ciclos pictóricos". En ZimmerMANN, N. (Hrsg.): Antike Malerei zwischen Lokalstil und Zeitstil. Akten des XI Internationalen Kolloquiums der AIPMA (Ephesos, 2010). Archäologische forschungen, Band 23. Wien, pp. 473-483.

Filloy, I.; Gil, E. e Iriarte, A. (1992): "La pintura mural romana en Álava: estado de la cuestión”. En JimÉNEZ, J. L. (ed.): I Coloquio de Pintura Mural Romana en España (Valencia-Alicante, 1989). Valencia: Univ. de Valencia, pp. 107-113.

Fontemaggi, A.; Piolanti, O. y Ravara, C. (2001): "Intonaci a motivi repetitivi da alcune domus riminesi”. En BARbet, A. (dir.): La peinture funéraire antique. IVe siècle av. J.-C.-IV siècle ap. J.-C. Actes du Colloque de l'AIPMA (Saint-Romain-en-Gal, Vienne, 1998). Paris: Érrance, pp. 273-276.

Formoso, E. (2006): “Le décors à réseau", Dossier d'Archéologie, 318, pp. 86-89.

Fuchs, M. (1989): Peintures romaines dans les collections suisses. Bulletin de Liaison du Centre du CEPMr, 9. Paris.

Fuchs, M. (1995): "Voûte peinte à Vallon (Suisse)", Revue Archéologique de Picardie, n. ${ }^{\circ}$ spécial 10, pp. 119-127.

Ghedini, F. y Salvadori, M. (2004): "Soffiti e pavimenti: un repertorio comune". En BorHy, L. (dir.): Plafonds et voûtes à l'époque antique. Actes du viIIe Colloque international de l'AIPMA (Budapest, 2001). Budapest: Pytheas Publishing, pp. 45-54.

GogräFe, R. (2002): "Wandmalereien aus der Villa rustica 'Ziegelscheuer' bei Ladenburg”. En LenZ-BERNHARD, G. (ed.): Lopodunum III. Die neckarswebische Siedlung und Villa rustica im Gewann Ziegelscheuer. Stuttgart: Theiss, pp. 601-606.

GonZÁleZ, E. (2005): Imago antiqua. Lugo romano. Lugo: Concello de Lugo.

Gozlan, S. (1992): La Maison du Triomphe de Neptune à Acholla (Botria, Tunise). I. Les Mosaïques. Roma: École Française de Rome.

Groetembril, S. y Vermeersch, D. (2017): “Tapisseries sur les murs, le décor d'une petite salle thermale du Thillay, au lieu-dit La Vieille-Baune". En
Boislève, J.; Dardenay, A. y Monier, F. (eds.): Peintures et stucs d'epoque romaine. Etudes toichographologiques. Actes du 28e colloque de l'AFPMA (Paris, 2015). Bordeaux: Pictor 7, pp. 97-110.

Guiral, C. (2018): "Un atelier provincial du in s.p.C. dans la vallée de l'Èbre (Espagne)". En BoislÈve, J.; Dardenay, A. y Monier, F. (eds.): Peintures et stucs d'époque romaine. Études toichographologiques. Actes du 29e colloque de l'AFPMA (Louvres, 2016). Pictor, 8. Bordeaux, pp. 137-148.

Guiral, C.; Fernández, A. y Cánovas, A. (2014): "En torno a los estilos locales en la pintura romana: el caso de Hispania en el s. II d. C.”. En Zimmermann, N. (Hrsg.): Antike Malerei zwischen Lokalstil und Zeitstil. Akten des XI. Internationalen Kolloquiums der AIPMA (Ephesos, 2010). Archäologische forschungen, Band 23. Wien, pp. 277-288.

Guiral, C.; ÍñIgueZ, L.; Fustes, J. y Fuchs, M. (2018): "La decoración pictórica del Municipium Urbs Victrix Osca (Huesca)", Veleia, 35, pp. 213-239.

Guiral, C. y Martín-Bueno, M. (1996): Bilbilis. Decoración pictórica y estucos ornamentales. Zaragoza: Institución Fernando el Católico.

Heras, F. J. (2011): Un edificio singular de la Mérida tardorromana: un posible centro de culto metróaco y rituales taurobólicos. Mérida: Instituto de Arqueología de Mérida.

Hevia, P.; Corral, R. M. y Sierra, N. (2007): “Excavación y restitución de las pinturas del viridarium de la Domus de las Columnas Rojas de Sisapo (La Bienvenida, Ciudad Real)”. En Guiral, C. (ed.): Circulación de temas y sistemas decorativos en la pintura mural antigua. Actas IX Congreso Internacional de l'AIPMA (Zaragoza-Calatayud, 2004). Zaragoza: Gob. de Aragón-unED, pp. 471-474.

Íñiguez, L.; Guiral, C.; Torrecilla, J. M. y HernánDEZ, J. A. (2021): “Graccurris (Alfaro, La Rioja) y la decoración de la Estancia 2 (Casa 4)”, Spal, 30 (1), pp. 258-289.

Í́̃iguez, L. y Rodríguez, P. (2020): "Programas pictóricos en el yacimiento de El Pueyo (Belchite, Zaragoza)". En Fernández Díaz, A. y Castillo, G. (eds.): La pintura romana en Hispania: del estudio de campo a su puesta en valor. Murcia: Univ. de Murcia, pp. 85-94.

JimÉnEZ, J. L. (2000): "Los hallazgos de pintura mural romana”. En Pascual, J. (ed.): L'arqueologia fa ciutat: les excavacions de la Plaça de Cisneros. Valencia: Ayto. de Valencia, pp. 31-34. 
Joyce, H. (1981): The Decoration of Walls Ceilings and Floors in Italy in the second and third centuries A.D. Roma: Giorgio Bretschneider.

Laken, L. (2001): "Wallpaper patterns in Pompeii and the Campanian Region: towards a Fifth Pompeian Style?". En Barbet, A. (dir.): La peinture funéraire antique. IV siècle av. J.-C.-IV siècle ap. J.-C. Actes Colloque de l'AIPMA (Saint-Romain-en-Gal, 1998). Paris: Errance, pp. 295-300.

Ling, R. (1991): Roman Painting. Cambridge: Cambridge University Press.

López, I.; Martín, C. y Martínez, R. (1994): Hallazgos arqueológicos en el Palau de Les Corts. Valencia: Corts Valencianes.

Mariani, E. (2005): "Domus C1. Gli affreschi grupo 8”. En Brogiolo, G. P.; Morandini, F. y Rossi, F. (a cura di): Dalle domus alla corte regia. S. Giulia di Brescia. Gli scavi dal 1980 al 1992. Brescia: All'Insegna del Giglio, pp. 147-154.

Mariani, E. (2013): "Lacerti di intonaco dipinto dal $\mathrm{Ca}$ pitolium Flavio". En Rossi, F. (a cura di): Un luogo per gli dei. L'area del Capitolium a Brescia. Firenze: All'Insegna del Giglio, pp. 389-392.

Mariani, E. y Pagani, C. (2012): "Considerazione critiche sugli aspetti e sugli sviluppi della pittura parietale delle regiones $\mathrm{X}$ e XI alla luce dei più recenti ritrovamenti”. En Oriolo, F. y Verzár, M. (eds.): $L a$ pittura romana nell'Italia settentrionale e nelle regioni limitrofe. Antichità Altoadriatiche, LxxIII. Trieste, pp. 41-58.

Martín, C.; Cabañero, V.; Martínez, S. y Gómez, C. (2020): "Nuevas aportaciones al conocimiento del conjunto pictórico del edificio de Los Cinco Caños, Coca, Segovia”. En Fernández, A. y Castillo, G. (eds.): La pintura romana en Hispania: del estudio de campo a su puesta en valor. Murcia: Univ. de Murcia, pp. 197-210.

Meyboom, P. y Moormann, E. (2013): Le decorazioni dipinte e marmoree della Domus Aurea di Nerone a Roma. Leuve-Paris-Walpole: Babesch.

MezQuíriz, M. A. (2009): Andelo, ciudad romana. Pamplona: Gob. de Navarra.

Mondy, M.; Freliger, N. y Boulaner, K. (2012): "Les thermes de la villa gallo-romaine de Damblain (Vosges)". En Fuchs, M. y Monier, F. (eds.): Les enduits peins en Gaule romaine. Approches croisées. Actes 23e Séminaire de l'AEPMA (Paris, 2009). Dijon: Revue archéologique de l'Est, pp. 217-228.

Mostalac, A. y Beltrán, M. (1994): Colonia Victrix Iulia Lepida-Celsa (Velilla de Ebro, Zaragoza) II.
Estratigrafía, pinturas y cornisas de la Casa de los Delfnes. Zaragoza: Diputación General de Aragón, Consejería de Educación y Cultura.

Noguera J. M.; Fernández Díaz, A. y Madrid, M. ${ }^{a}$ J. (2011): "Nuevas pinturas murales en Carthago Nova: los ciclos de las termas del foro y del edificio del atrio". En Noguera, J. M. y Madrid, M.a J. (eds.): Arx Hasdrubalis. La ciudad reencontrada. Arqueología en el Cerro del Molinete. Catálogo Exposición de Cartagena. Madrid: MAR, pp. 185-207.

ppM: Pompei, Pitture e mosaici. Roma: Istituto della Enciclopedia Italiana G. Treccani.

Provenzale, V. (2005): "Contributo preliminare allo studio degli intonaci del cosiddeto 'Tempio Gallet'”. En Cuscito, G. y Verzár-Bass, M. (eds.): Aquileia dalle origini alla costituzione del ducato Longobardo. La cultura artistica in età romana (II secolo a. C.-III secolo d. C.). Antichità Altoadriatiche, LXI. Trieste, pp. 471-485.

Rinaldi, F. (2005): "Il mosaico cd. del Tappeto fiorito". En Cuscito, G. y Verzar-Bass, M. (eds.): Aquileia dalle origini alla costituzione del ducato longobardo. $\mathrm{La}$ cultura artistica in età romana (II secolo a. C.-III secolo d. C.). Aquileia: Editreg, pp. 391-418.

SabriÉ, M. y R. (1994): "Le Clos de la Lombarde à Narbonne. Peintures murales de la maison III", Revue Archéologique de Narbonnaise, 27-28, pp. 191-295.

Salvadori, M. (2017): Horti picti. Forma e significato del giardino dipinto nella pittura romana. Padova: $\mathrm{Pa}-$ dova University Press.

SÁnchez Montes, A. L. (2015): "La pintura mural romana en el territorio complutense: privatorum aedificiorum ornamenta". En Pintura mural en la comunidad de Madrid. Madrid: Comunidad de Madrid, pp. 45-71.

Sánchez Montes, A. L. y Rascón, S. (2004): "La pintura mural de la Casa de los Grifos. Una nueva y excepcional domus de la ciudad romana de Complutum (Alcalá de Henares, Madrid, España)". En Guiral, C. (ed.): Circulación de temas y sistemas decorativos en la pintura mural antigua. Actas IX Congreso Internacional de la AIPMA (Zaragoza-Calatayud, 2004). Zaragoza: Gob. de Aragón-Uned, pp. 455-459.

SCAGLiarini, D. (1985-1987): "Architettura e decorazione nelle domus e nelle villae dell'Emilia e Romagna”, Centro di Studi Lunensi. Quaderni, 10-12, pp. 567-596.

Seiler, F. (1980): Casa degli Amorini Dorati [Häuser in Pompeji 5]. München: Hirmer.

Zephyrus, LXXXVIII, julio-diciembre 2021, 163-189 
StARAC, A. (2012): "La decorazione parietale della domus del quartiere di San Teodoro di Pola". En Oriolo, F. y Verzár, M. (eds.): La pittura romana nell'Italia settentrionale e nelle regioni limitrofe. Trieste: Editreg, pp. 241-250.

SuÁrez, L. y Fernández DíAz, A. (2006): "La Gorgona/ Medusa en el pavimento de una domus de la ciudad de Carthago Nova: un unicum en un conjunto de mosaicos geométricos y bicromos", Anales de Prehistoria y Arqueología, 22, pp. 75-110.
Taccalite, F. (2004): "La cd. 'Villa Grande' sotto la basilica di San Sebastiano fuori le Mura di Roma". En Borhy, L. (dir.): Plafonds et voûtes à l'époque antique. Actes du viIIe Colloque international de l'AIPMA (Budapest, 2001). Budapest: Pytheas Publishing, pp. 407-411.

Tessariol, M. (2016): "Décors de Bordeaux, un premier bilan de recherches”. En Boislève, J.; Dardenay, A. y Monier, F. (eds.): Peintures et stucs d'époque romaine. Une archéologie du décor. Actes $27^{\circ}$ Colloque de l'AFPMA (Toulouse, 2014). Pictor, 5. Bordeaux, pp. 27-36. 